\title{
Chemical Bonding in TI Cuprates Studied by X-ray Photoemission
}

\author{
R. P. Vasquez \\ Center for Space Microelectronics Technology, Jet Propulsion Laboratory, \\ California Institute of Technology, Pasadena, California 91109-8099 \\ M. P. Siegal and D. L. Overmyer \\ Sandia National Laboratories, Albuquerque, New Mexico 87185-1421
}

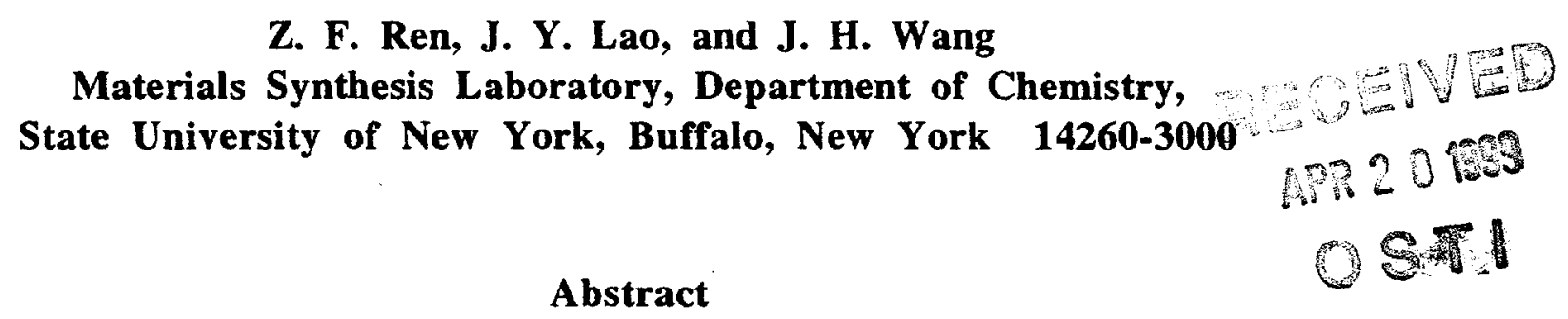

Epitaxial thin films of the $\mathrm{Tl}$ cuprate superconductors $\mathrm{Tl}_{2} \mathrm{Ba}_{2} \mathrm{CaCu}_{2} \mathrm{O}_{8}, \mathrm{Tl}_{2} \mathrm{Ba}_{2} \mathrm{Ca}_{2} \mathrm{Cu}_{3} \mathrm{O}_{10}$, and $\mathrm{Tl}_{0.78} \mathrm{Bi}_{0.22} \mathrm{Ba}_{0.4} \mathrm{Sr}_{1.6} \mathrm{Ca}_{2} \mathrm{Cu}_{3} \mathrm{O}_{9-\delta}$ are studied with $\mathrm{x}$-ray photoemission spectroscopy. These data, together with previous measurements in this lab of $\mathrm{Tl}_{2} \mathrm{Ba}_{2} \mathrm{CuO}_{6+\delta}$ and $\mathrm{TlBa}_{2} \mathrm{CaCu}_{2} \mathrm{O}_{7-\delta}$, comprise a comprehensive data set for a comparative study of $\mathrm{Tl}$ cuprates with a range of chemical and electronic properties. In the $\mathrm{Cu} 2 \mathrm{p}$ spectra, a larger energy separation between the satellite and main peaks $\left(E_{s}-E_{m}\right)$ and a lower intensity ratio $\left(\mathrm{I}_{s} / \mathrm{T}_{m}\right)$ are found to correlate with higher values of $T_{c}$. Analysis of these spectra within a simple configuration interaction model suggests that higher values of $T_{c}$ are related to low values of the $\mathrm{O} 2 \mathrm{p} \rightarrow \mathrm{Cu} 3 \mathrm{~d}$ charge transfer energy. In the $\mathrm{O}$ 1s region, a smaller bond length between $\mathrm{Ba}$ and $\mathrm{Cu}-\mathrm{O}$ planar oxygen is found to correlate with a lower binding energy for the signal associated with $\mathrm{Cu}-\mathrm{O}$ bonding, most likely resulting from the increased polarization screening by $\mathrm{Ba}^{2+}$ ions. For samples near optimum doping, maximum $\mathrm{T}_{\mathrm{c}}$ is observed to occur when the $\mathrm{Tl} 4 \mathrm{f}_{72}$ binding energy is near $117.9 \mathrm{eV}$, which is near the middle of the range of values observed for $T 1$ cuprates. Higher $T 14 f_{7 / 2}$ binding energies, corresponding to formal oxidation states nearer $\mathrm{Tl}^{1+}$, are also found to correlate with longer bond lengths between $\mathrm{Ba}$ and Tl-O planar oxygen, and with higher binding energies of the $\mathrm{O}$ is signal associated with Tl-O bonding. 


\section{DISCLAIMER}

This report was prepared as an account of work sponsored by an agency of the United States Government. Neither the United States Government nor any agency thereof, nor any of their employees, make any warranty, express or implied, or assumes any legal liability or responsibility for the accuracy, completeness, or usefulness of any information, apparatus, product, or process disclosed, or represents that its use would not infringe privately owned rights. Reference herein to any specific commercial product, process, or service by trade name, trademark, manufacturer, or otherwise does not necessarily constitute or imply its endorsement, recommendation, or favoring by the United States Government or any agency thereof. The views and opinions of authors expressed herein do not necessarily state or reflect those of the United States Government or any agency thereof. 


\section{DISCLAIMER}

Portions of this document may be illegible in electronic image products. Images are produced from the best available original document. 


\section{Introduction}

The Tl-based tetragonal cuprate superconductors of the form $\mathrm{Tl}_{m} \mathrm{Ba}_{2} \mathrm{Ca}_{\mathrm{n}-\mathrm{i}} \mathrm{Cu}_{\mathrm{n}} \mathrm{O}_{2 \mathrm{n}+\mathrm{m}+2 \pm \delta}$ $(\mathrm{m}=1,2 ; \mathrm{n}=1,2,3)$, commonly abbreviated to Tl-m2(n-1)n, are a class of materials in which the chemical and electronic properties, for which photoemission is a sensitive probe, vary with the number of $\mathrm{Tl}-\mathrm{O}$ and $\mathrm{Cu}-\mathrm{O}$ layers. In tetragonal cuprate superconductors, a van Hove singularity (VHS) is typically located near or below the Fermi level $\left(E_{F}\right),{ }^{1}$ thus requiring synthesis in an oxidizing atmosphere to optimize the hole doping and the superconducting transition temperature $\mathrm{T}_{c}$, as in the double T1-O layer materials. However, the stoichiometric $(\delta=0)$ single Th-O layer materials are hole overdoped and a VHS lies above $E_{F}{ }^{2}$ thus oxygen deficiency, sometimes requiring post-synthesis annealing in a reducing atmosphere, ${ }^{3-5}$ or partial substitution of trivalent rare earth ions on the $\mathrm{Ca}$ site ${ }^{6}$ is necessary for optimum $\mathrm{T}_{\mathrm{c}^{*}}$. The variation of $\mathrm{E}_{\mathrm{F}}$ with oxygen stoichiometry is detectable in rigid shifts of the photoemission core levels, as previously reported for T1-2201 (Ref. 7) and T1-1212 (Ref. 2).

The $\mathrm{Cu}-\mathrm{O}$ bonding varies with the number of $\mathrm{Cu}-\mathrm{O}$ layers, with the oxygen coordination being distorted octahedral ${ }^{8}$ for $n=1$, square pyramidal ${ }^{9,10}$ for $n=2$, and a mixture of square pyramidal (outer $\mathrm{Cu}-\mathrm{O}$ layers) and square planar (middle $\mathrm{Cu}-\mathrm{O}$ layer) ${ }^{10-12}$ for $\mathrm{n}=3$. It has been proposed that such differences in $\mathrm{Cu}-\mathrm{O}$ bonding result in differences in $\mathrm{Cu}$ - apical oxygen charge transfer which are detectable in the $\mathrm{Cu} 2 \mathrm{p}$ photoemission spectra. ${ }^{13}$ The $\mathrm{Cu} 2 \mathrm{p}$ spectra have also been analyzed within a simple configuration interaction model utilizing a two-band Hamiltonian. ${ }^{1417}$ Within this model, the $\mathrm{O} 2 \mathrm{p} \rightarrow \mathrm{Cu} 3 \mathrm{~d}$ charge transfer energy $\Delta$, the $\mathrm{O} 2 \mathrm{p}-$ $\mathrm{Cu} 3 \mathrm{~d}$ hybridization strength $\mathrm{T}$, and the on-site Coulomb interaction between $\mathrm{Cu} 2 \mathrm{p}$ and $\mathrm{Cu} 3 \mathrm{~d}$ holes $U$, are related to the experimentally-determined energy separation between the poorlyscreened satellite and well-screened main peak $\left(E_{s}-E_{m}\right)$ and to the ratio of the intensities of the satellite and main peak $\left(\mathrm{I}_{\mathrm{s}} / \mathrm{I}_{\mathrm{m}}\right)$. Attempts to determine systematic trends in the $\mathrm{Cu}-\mathrm{O}$ bonding parameters for the superconducting cuprates have yielded contradictory results, with some studies reporting that $I_{s} I_{m}$ (and $\Delta T$ ) increases with increasing $T_{c}$ (e.g. Refs. 18,19) and other studies reporting the opposite (e.g. Refs. 20,21). These contradictory results may be related to differences 
in doping (oxygen content) between the samples studied by different groups, at least in the surface region probed by photoemission, since $I_{s} / I_{m}$ depends sensitively on doping. ${ }^{16,18 \cdot 20}$ Surface preparation which avoids loss of oxygen is thus critical in such studies.

The Tl-O bonding also varies with the number of Tl-O layers, with $\mathrm{Tl}$ being bonded to (in addition to the long planar Tl-O bonds) two apical oxygens $s^{9,11,12}$ for $\mathrm{m}=1$, and to one apical oxygen and one oxygen in the adjacent $\mathrm{Tl}-\mathrm{O}$ layer $^{910}$ for $\mathrm{m}=2$. It has been reported that the single and double T1-O layer materials have distinguishable photoemission spectra which reflect differences in charge transfer between $\mathrm{Tl}-\mathrm{O}$ and $\mathrm{Cu}-\mathrm{O}$ layers. ${ }^{22}$

In this work, $\mathrm{x}$-ray photoemission spectroscopy (XPS) measurements of T1-2212, T1-2223, and the Tl-1223 phase $\mathrm{Tl}_{0.78} \mathrm{Bi}_{0.22} \mathrm{Ba}_{0.4} \mathrm{Sr}_{1.6} \mathrm{Ca}_{2} \mathrm{Cu}_{3} \mathrm{O}_{9-8}((\mathrm{Tl}, \mathrm{Bi})-1223)$ are reported which, together with previously reported measurements in this lab of Tl-2201 (Ref. 7) and Tl-1212 (Ref. 2), comprise a comprehensive comparative study of $\mathrm{T} 1$ cuprates with a range of chemical and electronic properties. These results are compared to earlier studies which have included comparison of several $\mathrm{Tl}$ cuprates, ${ }^{20-23}$ as well as studies of individual $\mathrm{Tl}$ cuprate phases. ${ }^{20,2426}$

\section{Experimental}

Two epitaxial films each of Tl-2212 (6000 $\AA$-thick) and T1-2223 (4300 $\AA$-thick) on $\mathrm{LaAlO}_{3}$ (100) substrates are obtained by sputter deposition of Tl-free precursor films followed by an $e x$ situ anneal together with Tl-rich T1-2223 pellets in an alumina crucible for thallination. Details of the film growth, annealing, and characterization are described elsewhere. ${ }^{27}$ The zero-resistance temperatures of the $\mathrm{Tl}-2223$ films are $112.5 \mathrm{~K}$ and $114 \mathrm{~K}$, and the $\mathrm{Tl}-2212$ films have Meissner transitions at $102 \mathrm{~K}$ as determined with a SQUID magnetometer. Five $1 \mu \mathrm{m}$-thick epitaxial films of $(\mathrm{Tl}, \mathrm{Bi})-1223$ are grown on $\mathrm{LaAlO}_{3}(100)$ substrates by laser ablation, followed by post-growth annealing of the films wrapped in $\mathrm{Ag}$ foil together with $\mathrm{Tl}-\mathrm{rich}$ (T1,Bi)-1223 pellets. This procedure typically yields films with zero-resistance temperatures in the range $105-111 \mathrm{~K}$. Details of the film growth, annealing, and characterization are described elsewhere. ${ }^{28,29}$ Epitaxial 
films of the rare earth cuprates $\mathrm{La}_{2} \mathrm{CuO}_{4}, \mathrm{Nd}_{2} \mathrm{CuO}_{4}$, and $\mathrm{Gd}_{2} \mathrm{CuO}_{4}$ are grown by pulsed laser deposition in $100 \mathrm{mTorr}$ background pressure of oxygen onto $\mathrm{LaAlO}_{3}(100)$ substrates at $650^{\circ} \mathrm{C}$.

The film surfaces are cleaned in a dry box with an inert ultrahigh purity $\mathrm{N}_{2}$ atmosphere which encloses the load lock area of the XPS spectrometer using a nonaqueous etchant consisting of $0.1 \% \mathrm{Br}_{2}$ in absolute ethanol for $15-60$ seconds (etch rate $-1000 \AA$ minute), rinsed in ethanol, and loaded into the XPS spectrometer with no atmospheric exposure. The XPS spectrometer is a Surface Science Instruments SSX-501 utilizing monochromatic Al $\mathrm{K}_{\alpha} \mathrm{X}$-rays $(1486.6 \mathrm{eV})$. Spectra are measured at ambient temperature with photoemission normal to the surface. The core level spectra are measured with an $\mathrm{x}$-ray spot size of $150 \mu \mathrm{m}$ and the pass energy of the electron energy analyzer is set to $25 \mathrm{eV}$. The energy scale is calibrated using sputter-cleaned $\mathrm{Au}$ and $\mathrm{Cu}$ with the $\mathrm{Au} 4 \mathrm{f}_{72}$ binding energy set to $83.95 \pm 0.05 \mathrm{eV}(0.7 \mathrm{eV}$ full width at half-maximum (FWHM)) and the $\mathrm{Cu} 2 \mathrm{p}_{3 / 2}$ binding energy set to $932.45 \pm 0.05 \mathrm{eV}(1.0 \mathrm{eV}$ FWHM). The surface preparation, XPS spectrometer characteristics, and measurement conditions are described in more detail elsewhere. ${ }^{2.7}$

The measured surface stoichiometries normalized to $\mathrm{Cu}$ are $\mathrm{Tl}: \mathrm{Ba}: \mathrm{Ca}: \mathrm{Cu}: \mathrm{O}=1.65: 2.1: 2.25: 3$ for the Tl-2223 films, Tl:Ba:Ca:Cu:O = 2:2.2:1.2:2 for the Tl-2212 films, and $\mathrm{Tl}: \mathrm{Bi}: \mathrm{Sr}: \mathrm{Ba}: \mathrm{Ca}: \mathrm{Cu}: \mathrm{O}=0.8: 0.3: 1.6: 0.5: 1.8: 3$ for the $(\mathrm{Tl}, \mathrm{Bi})-1223$ films. The slight deviations from the expected bulk stoichiometries may result from residual surface and/or grain boundary contaminants, evident in the XPS spectra as residual high binding energy signals in the $O$ is and alkaline earth core level regions, or from the layered nature of these materials, since the c-axis lattice constants are comparable to or greater than typical photoelectron attenuation lengths. The (Tl,Bi)-1223 films have a Ag contaminant present at a level of 1 - 2 atomic percent, presumably from the annealing procedure, which contributes a detectable small feature to the valence band spectra, as discussed later.

After completion of the XPS measurements, ac susceptibility determinations of $T_{c}$ (typically slightly lower than zero-resistance temperatures) were performed. The measured onsets of the superconducting transition temperature and transition widths $\Delta T_{c}$ for the Tl-2223 films are $T_{c}=$ 
$109 \mathrm{~K}$ and $111 \mathrm{~K}$ and $\Delta \mathrm{T}_{\mathrm{c}}=2 \mathrm{~K} ; \mathrm{T}_{\mathrm{c}}=103-106 \mathrm{~K}$ and $\Delta \mathrm{T}_{\mathrm{c}}=1 \mathrm{~K}$ for the $(\mathrm{T}, \mathrm{Bi})-1223$ films; and $T_{c}=102 \mathrm{~K}$ and $104 \mathrm{~K}$ and $\Delta \mathrm{T}_{\mathrm{c}}=1 \mathrm{~K}$ for the Tl-2212 films.

\section{Results and Discussion}

The results of the XPS measurements of core levels other than the $\mathrm{Cu} 2 \mathrm{p}$ are summarized in Table I for 16 samples of the 5 different $\mathrm{Tl}$ cuprate phases measured in this lab, as well as previous measurements in this $\mathrm{lab}^{30}$ for epitaxial films of $\mathrm{HgBa}_{2} \mathrm{CaCu}_{2} \mathrm{O}_{6+\delta}(\mathrm{Hg}-1212)$, which is chemically and structurally closely related to the $\mathrm{Tl}$ cuprates. The core level binding energies are determined from least squares fitting for the $\mathrm{Tl} 4 \mathrm{f}$ and $\mathrm{Ba} 3 \mathrm{~d}$ and $4 \mathrm{~d}$ signals, which consist of a single component or which contain components which are well separated. For the $\mathrm{Ca} 2 \mathrm{p}$ and $\mathrm{O}$ is signals, which consist of components with significant overlap, the uncertainty in the least squares fitting is considerably greater, with the determined binding energies varying by as much as $0.2 \mathrm{eV}$ (but typically $<0.1 \mathrm{eV}$ ) for the same spectrum with different initial fitting parameters. The binding energies for these core levels listed in Table I are therefore those determined from the second derivatives, for which the variability is generally comparable to the other core levels.

XPS measurements of the $\mathrm{Cu} 2 \mathrm{p}$ core levels for the $\mathrm{Tl}$ and rare earth cuprates are summarized in Table II, together with previous measurements in this lab for Hg-1212 (Ref. 30), $\mathrm{Bi}_{2} \mathrm{Sr}_{2} \mathrm{CaCu}_{2} \mathrm{O}_{8}(\mathrm{Bi}-2212),{ }^{31}$ and $\mathrm{YBa}_{2} \mathrm{Cu}_{3} \mathrm{O}_{7}(\mathrm{Y}-123){ }^{32}$ The $\mathrm{Cu} 2 \mathrm{p}_{32}$ satellite to main peak intensity ratios $\left(\mathrm{H} / \mathrm{I}_{\mathrm{m}}\right)$ are determined from the integrated intensities above a flat background from the smoothed spectra, and the positions listed in Table II are the centroids. The data in Tables I and II show that the measurements from different films of the same phase with similar $T_{c} s$ are very similar, demonstrating good sample-to-sample reproducibility. The results for Tl-2212 are similar to previous measurements in this lab using films grown with a different technique and different photoemission measurement conditions. ${ }^{33,34}$

The $O$ 1s spectra for the five Tl cuprate phases considered here are shown in Fig. 1. The

signal near $531 \mathrm{eV}$ is dominant prior to etching and is associated with contaminants, particularly hydroxides and carbonates of the reactive alkaline earth elements. ${ }^{35}$ The lower binding energy 
manifold near $528 \mathrm{eV}$ consists of signals from the inequivalent lattice sites in the superconductors. This signal is clearly detectable prior to etching and the binding energy is not affected by the etching (as is also the case for the other core levels), an indication that the surface is not detectably damaged by the etching. The dominance of the lower binding energy signals evident in Fig. 1 is a measure of the surface quality achieved in this work. In earlier works on $\mathrm{Tl}$ cuprates, the $\mathrm{O}$ is signals were either not reported, ${ }^{19-21}$ making an assessment of the intrinsic nature of the measurements problematic, or the higher binding energy contaminant signals were significantly larger ${ }^{23,24}$ than those evident in Fig. 1.

\section{III. a. Cu-O Bonding}

Information on the $\mathrm{Cu}-\mathrm{O}$ bonding can be obtained from the $\mathrm{O} 1 \mathrm{~s}$ and $\mathrm{Cu} 2 \mathrm{p}$ core levels. The low binding energy $\mathrm{O} 1 \mathrm{~s}$ signal consists of two components, most clearly evident in the T1-2201 spectrum (bottom curve in Fig. 1), associated with $\mathrm{Cu}-\mathrm{O}$ bonding (lowest binding energy component) and Tl-O bonding ( $\sim 1 \mathrm{eV}$ higher binding energy). The two components are more clearly separated in the second derivatives shown in Fig. 2. The differing lineshapes evident in Fig. 1 result from differences in the energy separations of these two components (see Fig. 2) and from differences in the relative intensities due to the differing $\mathrm{T} / \mathrm{Cu}$ ratios in the various phases. A qualitative understanding of the observed $\mathrm{O} 1 \mathrm{~s}$ binding energies and their relationship to chemical bonding can be gained by consideration of the crystal structures of the various $\mathrm{Tl}$ cuprate phases. ${ }^{8-12}$ To avoid confusion related to the different atom numbering employed for the various phases, the $\mathrm{Cu}-\mathrm{O}$ planar oxygen in the single and double $\mathrm{Cu}-\mathrm{O}$ layer materials and in the outer $\mathrm{Cu}-\mathrm{O}$ layers of triple $\mathrm{Cu}-\mathrm{O}$ layer materials will be referred to as $\mathrm{O}(1)$, the $\mathrm{Cu}-\mathrm{O}$ planar oxygen in the middle $\mathrm{Cu}-\mathrm{O}$ layer of triple $\mathrm{Cu}-\mathrm{O}$ layer materials will be referred to as $\mathrm{O}\left(1^{\prime}\right)$, the apical oxygen (Ba-O layers) will be referred to as $\mathrm{O}(2)$, and oxygen in the Tl-O layers will be referred to as $\mathrm{O}(3)$.

In addition to in-plane coordination to two $\mathrm{Cu}$ atoms, each $\mathrm{O}(1)$ is coordinated to either four $\mathrm{Ba}^{2+}$ ions (Tl-2201) or two $\mathrm{Ba}^{2+}$ and two $\mathrm{Ca}^{2+}$ ion (Tl-n212 and the outer $\mathrm{Cu}-\mathrm{O}$ planes in $\left.\mathrm{Tl}-\mathrm{n} 223\right)$ and each $\mathrm{O}\left(\mathrm{l}^{\prime}\right)$ is coordinated to four $\mathrm{Ca}^{2+}$ ions. There appears to be no correlation of the $\mathrm{O}$ ls 
binding energies and the $\mathrm{Cu}-\mathrm{O}$ bond lengths, which for the $\mathrm{Tl}$ cuprates considered here are all near $1.93 \AA$ with the exception of (Tl,Bi)-1223 which has $\mathrm{Cu}-\mathrm{O}$ bond lengths of $1.91 \AA$. However, as shown in Fig. 3, $\mathrm{O}\left(1,1^{\prime}\right) \mathrm{O}$ ls binding energies are correlated with the much longer $\mathrm{Ba}-\mathrm{O}(1)$ bond lengths (2.73-2.84 $\AA$, due to the larger $\mathrm{Ba}^{2+}$ ionic radius), with lower $\mathrm{O}$ 1s binding energies occurring for shorter $\mathrm{Ba}-\mathrm{O}(1)$ bond lengths. Since the $(\mathrm{Ba}, \mathrm{Sr})-\mathrm{O}(1)$ bond length determined by powder neutron diffraction ${ }^{12}$ in $(\mathrm{Tl}, \mathrm{Bi})-1223$ is an average, the local $\mathrm{Ba}-\mathrm{O}(1)$ bond length is assumed to be the same as in Tl-1223 (Ref. 11). Also included in Fig. 3 is Hg-1212 using previously reported XPS measurements from this $\mathrm{lab}^{30}$ and the crystal structure reported in the literature. ${ }^{36}$ Contributions to a lower $\mathrm{O} 1 \mathrm{~s}$ binding energy resulting from a shorter $\mathrm{Ba}-\mathrm{O}(1)$ bond length include an increased Madelung energy at the $O(1)$ site (assuming other contributions to the Madelung energy remain constant) and increased polarization screening of the photoionized $O$ is core hole final state. If the effect of the alkaline earth - O(1) bond length on the Madelung energy is the dominant effect, then one would expect that the $\mathrm{O}$ 1s binding energy for Tl-2201 (four $\mathrm{Ba}-\mathrm{O}(1)$ bonds) would be higher than for the other $\mathrm{Tl}$ cuprates (two $\mathrm{Ba}-\mathrm{O}(1)$ and two $\mathrm{Ca}-\mathrm{O}(1)$ bonds, or four $\mathrm{Ca}-\mathrm{O}\left(1^{\prime}\right)$ bonds), since the $\mathrm{Ca}-\mathrm{O}\left(1,1^{\prime}\right)$ bond lengths are much shorter than the $\mathrm{Ba}$ $\mathrm{O}(1)$ bond lengths. This is the opposite of what is observed. Alternatively, if the polarization screening is the dominant effect, then the $\mathrm{O} 1 \mathrm{~s}$ binding energy for Tl-2201 would be lower than for the other $\mathrm{Tl}$ cuprates, which is consistent with the measurements presented here, since the polarizability of $\mathrm{Ba}^{2+}$ is more than triple that of $\mathrm{Ca}^{2+}$ (Ref. 37). Though not conclusive, the correlation evident in Fig. 3 thus suggests that the final state screening is the dominant contributor to the observed differences in the $\mathrm{O}$ 1s binding energies evident in Figs. 2 and 3.

Representative $\mathrm{Cu} 2 \mathrm{p}_{3 / 2}$ spectra are presented in Fig. 4. The multiplet at higher binding energy, referred to as a satellite peak in the literature, corresponds to states of predominant $2 p^{5} 3 d^{9} L$ character, where underscoring denotes a hole and $\mathrm{L}$ is the oxygen ligand, while the main peak at lower binding energy corresponds to states of predominant $2 p^{5} 3 d^{10} \mathrm{~L}$ character resulting from ligand-to-metal $(\mathrm{O} 2 \mathrm{p} \rightarrow \mathrm{Cu} 3 \mathrm{~d})$ charge transfer. ${ }^{14.17 .38}$ It is to be noted that the values of $\mathrm{L}_{\mathrm{m}}$ in Table II are at the high end of the range of values found in the literature, e.g. for Tl-2223 the value 
of 0.38-0.39 in this work compares to previously reported values of 0.19 (Ref. 20), 0.24 (Refs. 19,21), 0.21 and 0.38 (Ref. 24), and 0.38 (Ref. 23). The variability in reported results is likely due to problems in reproducibly obtaining high quality surfaces, since typically surface preparation consists of scraping a polycrystalline pellet in vacuum, which has been reported to cause reduction of $\mathrm{Cu}^{2+}$ to $\mathrm{Cu}^{1+}$ (i.e. low values of $\mathrm{I}_{\mathrm{m}}$ ) for other cuprate superconductors. ${ }^{35,39,40}$

As shown in Fig. 5, higher values of $T_{c}$ are correlated with lower values of $I_{s} / I_{m}$ for samples near optimum doping. This trend is consistent with some earlier reports, ${ }^{20,21}$ despite the differences in reported values of $I_{s} / I_{m}$, and is in contradiction to other studies. ${ }^{18,19}$ We now consider factors which may explain such a correlation. As previously mentioned, $I / I_{m}$ and $E_{s}-E_{m}$ are related to the parameters $\Delta(\mathrm{O} 2 \mathrm{p} \rightarrow \mathrm{Cu} 3 \mathrm{~d}$ charge transfer energy), T (Cu $3 \mathrm{~d}-\mathrm{O} 2 \mathrm{p}$ hybridization energy), and $U$ (on-site Coulomb interaction between $\mathrm{Cu} 2 \mathrm{p}$ and $3 \mathrm{~d}$ holes) in a simple configuration interaction model. ${ }^{1417}$ Although the two experimentally-determined quantities are insufficient to uniquely determine the three model parameters, the data set in Table $I$ is sufficient to restrict their values to narrow ranges. The experimental values of $I_{s} / L_{m}$ and $E_{s}-E_{m}$ in Table II for all of the superconducting cuprates are reproduced in calculations for $\Delta=0.5-1.0 \mathrm{eV}$, $\mathrm{T}=2.2-2.5 \mathrm{eV}$, and $\mathrm{U}=7.6-8.0 \mathrm{eV}$. If the oxygen-oxygen interaction is included in the calculations and fixed at $0.5 \mathrm{eV}$, as in Ref. 15, then $\Delta=-0.5$ to $0 \mathrm{eV}$. This range of values for $\Delta$ corresponds to $\mathrm{Cu} d$ orbital occupancy $\mathrm{n}_{\mathrm{d}} \sim 9.4$, characteristic of strong mixed valency as previously noted..$^{15}$

Comparison of the measured values of $\mathrm{I}_{\mathrm{s}} / \mathrm{I}_{\mathrm{m}}$ and $\mathrm{E}_{\mathrm{s}}-\mathrm{E}_{\mathrm{m}}$ with the values calculated as $\Delta$ or $\mathrm{T}$ is varied with the other two model parameters fixed is shown in Fig. 6. Decreasing values of $\mathrm{I}_{s} / \mathrm{I}_{\mathrm{m}}$ and increasing values of $E_{s}-E_{m}$ are reasonably well explained qualitatively by calculations with either decreasing values of $\Delta$ or increasing values of $\mathrm{T}$, i.e. more covalent $\mathrm{Cu}-\mathrm{O}$ bonding. $\mathrm{T}$ is to first order proportional to $\mathrm{d}_{\mathrm{Cu}-\mathrm{O}}^{-4}$ (Ref. 17), where $\mathrm{d}_{\mathrm{Cu}-\mathrm{O}}$ is the $\mathrm{Cu}-\mathrm{O}$ bond length. Since the $\mathrm{Tl}$ cuprates, as well as $\mathrm{Hg}-1212$, have very similar $\mathrm{Cu}-\mathrm{O}$ bond lengths, then variation of $\Delta$ is likely to be the dominant cause of changes in $\mathrm{I}_{\mathrm{m}} \mathrm{I}_{\mathrm{m}}$ and $\mathrm{E}_{\mathrm{s}}-\mathrm{E}_{\mathrm{m}}$. The correlation evident in Fig. 5 therefore 
suggests that higher values of $T_{c}$ are related to low values of the $\mathrm{O} 2 \mathrm{p} \rightarrow \mathrm{Cu} 3 \mathrm{~d}$ charge transfer energy.

Finally, we consider the effects of differences in oxygen coordination on the $\mathrm{Cu}-\mathrm{O}$ bonding as reflected in the $\mathrm{Cu} 2 \mathrm{p}$ spectra. In studies comparing the $\mathrm{Cu} 2 \mathrm{p}$ spectra measured from $\mathrm{La}_{2} \mathrm{CuO}_{4}$ (distorted octahedral $\mathrm{O}$ coordination to $\mathrm{Cu}$ ) and $\mathrm{Nd}_{2} \mathrm{CuO}_{4}$ (square planar coordination), it has been reported that in the latter compound the main line is narrower. ${ }^{13}$ The proposed explanation was that $\mathrm{O} 2 \mathrm{p}_{\mathrm{x}, y} \rightarrow \mathrm{Cu} 3 \mathrm{~d}_{x^{2}-y^{2}}$ charge transfer occurs in both compounds, while $\mathrm{O} 2 \mathrm{p}_{\mathrm{z}} \rightarrow \mathrm{Cu} 3 \mathrm{~d}_{\mathrm{z}^{2}}$ charge transfer is possible only in $\mathrm{La}_{2} \mathrm{CuO}_{4}$. The additional charge transfer pathway results in an additional contribution to the main peak, and thus a broader and asymmetric signal, as is also observed in high temperature superconductors. To verify this, measurements on $\mathrm{La}_{2} \mathrm{CuO}_{4}$, $\mathrm{Nd}_{2} \mathrm{CuO}_{4}$, and $\mathrm{Gd}_{2} \mathrm{CuO}_{4}$ (which has the $\mathrm{Nd}_{2} \mathrm{CuO}_{4}$ crystal structure and square planar $\mathrm{O}$ coordination to $\mathrm{Cu}$ ) have been done in this work, and the results are included in Table II. A possible problem with the scenario described above is that, in the absence of other differences, with the additional charge transfer one might also expect $\mathrm{I}_{\mathrm{m}} \mathrm{I}_{\mathrm{m}}$ to be lower for $\mathrm{La}_{2} \mathrm{CuO}_{4}$, while the opposite is observed in this work as well as in earlier studies. ${ }^{17,41,42}$ Among the $\mathrm{Tl}$ cuprates, T1-2201 with octahedral coordination also exhibits a higher value of $\mathrm{L} / \mathrm{I}_{\mathrm{m}}$ compared to the other cuprates which have pyramidal or mixed pyramidal and square planar coordination (see Table II). The measured widths of the $\mathrm{Cu} 2 \mathrm{p}$ main peaks are also larger for $\mathrm{Nd}_{2} \mathrm{CuO}_{4}$ and $\mathrm{Gd}_{2} \mathrm{CuO}_{4}$ than for $\mathrm{La}_{2} \mathrm{CuO}_{4}$, which is also contrary to expectations based on the model described above. The suggestion that the peak shapes of the main $\mathrm{Cu} 2 \mathrm{p}$ signals reflect the specific suggested differences in charge transfer pathways therefore does not appear to be supported by the measurements in this work.

\section{III. b. Tl-O Bonding}

Information on the $\mathrm{Tl}-\mathrm{O}$ bonding can be obtained from the $\mathrm{Tl} 4 \mathrm{f}$ spectra and the higher binding energy component of the $O$ ls spectra. Representative $\mathrm{Tl} 4 \mathrm{f}$ spectra measured from each of the five $\mathrm{Tl}$ cuprate phases measured in this lab are presented in Fig. 7. The spectra are well 
represented by a single doublet in the expected $4: 3$ intensity ratio, consistent with a single $\mathrm{T}$ chemical state. The higher binding energy component of the $\mathrm{O}$ is spectra originates from Tl-O bonds, which are to $O(2,3) p_{z}$ states as discussed below.

Crystal structure determinations $\mathrm{s}^{8-12}$ show that the in-plane $\mathrm{Tl}-\mathrm{O}(3)$ distances are much longer than T1-O distances in the $\mathrm{c}$ direction, which are $\mathrm{Tl}$ bonds to the $\mathrm{O}(2)$ (apical) oxygens, and in the case of the double Tl-O layer materials also to $\mathrm{O}(3)$ in the adjacent T1-O layers. Band structure calculations ${ }^{2,43,44}$ also show that the in-plane Tl-O(3) $\mathrm{p}_{x, y}$ interactions are weak, while the stronger $\mathrm{Tl} 6 \mathrm{~s}-\mathrm{O}(2,3) \mathrm{p}_{\mathrm{z}}$ covalent interactions yield hybridized states. For the double Tl-O layer materials, the hybridized states form occupied bonding bands of predominant $\mathrm{Tl}$ 6s character which are $\sim 7 \mathrm{eV}$ below the Fermi energy, and antibonding bands of predominant $O(2,3) p_{z}$ character which are $\sim 0-2$ $\mathrm{eV}$ above the Fermi level and are nearly empty, but do dip slightly below the Fermi level forming electron pockets at the $\Gamma$ point, and also at the $\mathrm{Z}$ point for $\mathrm{Tl}-2212$ and $\mathrm{Tl}-2223$. For the single Tl-O layer materials the situation is similar, but both the bonding and antibonding bands are $\sim 2 \mathrm{eV}$ higher energy (lower binding energy) so that the antibonding bands are completely empty. In all cases states with significant $\mathrm{Tl} 6 \mathrm{~s}$ character are therefore occupied, so $\mathrm{Tl}$ should be viewed as mixed valent and in terms of formal oxidation state is intermediate between $\mathrm{Tl}^{1+}$ and $\mathrm{Tl}^{3+}$. However, Tl should not be viewed as discrete ions, some with occupied and some with empty $6 \mathrm{~s}$ orbitals, since the bands are dispersive and the electrons are thus delocalized.

Higher $\mathrm{Tl} 4 \mathrm{f}_{72}$ binding energies are correlated with higher $\mathrm{O}(2,3) \mathrm{O} 1 \mathrm{~s}$ binding energies, as shown in Fig. 8. Usually a higher metal core level binding energy indicates increased metal-toligand charge transfer and should be correlated with lower ligand core level binding energies. However, the higher $\mathrm{Tl}$ core level binding energies of $\mathrm{Tl}^{1+}$ compounds relative to $\mathrm{Tl}^{3+}$ compounds are well-documented, ${ }^{19,25,45,46}$ and have been attributed to enhanced final state relaxation in conductive $\mathrm{Tl}^{3+}$ compounds, ${ }^{45}$ though specific calculations or additional experimental evidence in support of this conjecture appear to be lacking. The data in Fig. 8 thus seem to be consistent with the view ${ }^{19,21-23,25,26}$ that the $\mathrm{Tl} 4 \mathrm{f}_{72}$ binding energies in $\mathrm{Tl}$ cuprates reflect mixed valent $\mathrm{Tl}$ (which is also consistent with band structure calculations), with single T1-O layer materials being closest to 
$\mathrm{Tl}^{3+}$. However, states with predominant $\mathrm{Tl} 6 \mathrm{~s}$ character in the single $\mathrm{Tl}-\mathrm{O}$ materials remain well below the Fermi level and hence are occupied and the formal oxidation state remains intermediate between $\mathrm{Tl}^{1+}$ and $\mathrm{Tl}^{3+}$. The observed variation of the $\mathrm{Tl}$ core level binding energies for the various phases may reflect differences in the occupation of the $\mathrm{Tl} 6 \mathrm{~s}$ states, or differences in the relative $\mathrm{Tl}$ $6 \mathrm{~s}$ character of the states.

Finally, for samples which are reasonably close to optimum doping we note a correlation between the $T l 4 f_{72}$ binding energy and $T_{c}$, with maximum $T_{c}$ occurring for $T 14 f_{7 n}$ binding energies near $117.9 \mathrm{eV}$, as shown in Fig. 9. This correlation is not evident for samples far from optimum doping, e.g. overdoped Tl-2201 $\left(T_{c}=11 \mathrm{~K}\right)$ also exhibits $T 14 \mathrm{f}_{7 \Omega}$ binding energies near $117.9 \mathrm{eV}$. The correlation evident in Fig. 9 appears similar in form to the correlation observed in a study ${ }^{47}$ of the effect of pressure on T1-2212, in which $T_{c}$ was found to be maximum for an optimum $\mathrm{Ba} \mathrm{z}$ coordinate. Indeed, comparing the crystal structures of the various $\mathrm{Tl}$ cuprate phases ${ }^{8-11}$ shows that $\mathrm{T}_{c}$ is maximum for a $\mathrm{Ba}-\mathrm{O}(3)$ distance near $2.85 \AA$, suggesting a relationship between the $\mathrm{Ba}-\mathrm{O}(3)$ bond length and the $\mathrm{T} 4 \mathrm{f}_{72}$ binding energy. This conjecture is confirmed in Fig. 10. The correlation evident in Fig. 10 is not surprising for double Tl-O layer materials, since $\mathrm{Tl}$ is bonded to $\mathrm{O}(3)$ atoms in the adjacent Tl-O layers. However, in single Tl-O layer materials, the only T1-O(3) interactions are the weak in-plane interactions, which suggests that other factors may be responsible, such as the Madelung energy or that charge transfer between the Tl-O and $\mathrm{Cu}-\mathrm{O}$ layers is mediated by the $\mathrm{Ba}^{2+}$ ions.

\section{III. c. Alkaline earth - oxygen bonding}

Representative $\mathrm{Ba} 4 \mathrm{~d}$ spectra measured from the five $\mathrm{Tl}$ cuprate phases considered in this work are presented in Fig. 11. Each spectrum consists of a dominant doublet at low binding energy corresponding to the superconducting phase, and a minor doublet at higher binding energy corresponding to residual surface contaminant phases. The spectra are consistent with $\mathrm{Ba}$ being in a single chemical state, and are comparable to $\mathrm{Ba} 4 \mathrm{~d}$ signals measured from other cuprate superconductors (e.g. see the review in Ref. 48). 
$\mathrm{Ba}$ is coordinated to four $\mathrm{O}(1)$ atoms, four $\mathrm{O}(2)$ atoms, and one $\mathrm{O}(3)$ atom. Band structure calculations ${ }^{2,43,44}$ show that the valence band states have little $\mathrm{Ba}$ or $\mathrm{Ca}$ character; to a good approximation the alkaline earths can therefore be considered to be ideally ionic. As previously noted, the $\mathrm{O}\left(1,1^{\prime}\right) \mathrm{O} 1 \mathrm{~s}$ binding energies are correlated with the $\mathrm{Ba}-\mathrm{O}(1)$ bond lengths (Fig. 3), and the $\mathrm{Tl} 4 \mathrm{f}_{72}$ binding energies are correlated with the $\mathrm{Ba}-\mathrm{O}(3)$ bond lengths (Fig. 10). The Ba $4 \mathrm{~d}_{S \Omega}$ binding energies, on the other hand, do not correlate with any individual $\mathrm{Ba}-\mathrm{O}$ bond length. However, a reasonable correlation with the average $\mathrm{Ba}-\mathrm{O}$ bond length $\langle\mathrm{R}(\mathrm{Ba}-\mathrm{O})\rangle$ is evident, as shown in Fig. 12, with lower $\left\langle R(B a-O)>\right.$ corresponding to lower $\mathrm{Ba} 4 \mathrm{~d}_{5 / 2}$ binding energies, though a larger deviation from the trend line is apparent for data measured from Tl-1212 samples compared to data measured from the other $\mathrm{Tl}$ cuprate phases. The observed trend is consistent with both the increased Madelung energy and with increased polarization screening of the $\mathrm{Ba}^{2+}$ ions with smaller $\mathrm{Ba}-\mathrm{O}$ bond lengths. While both effects are expected to contribute to the observations, previous studies of simple alkaline earth salts have shown that the Madelung energy is the dominant factor. ${ }^{49-51}$

Representative Ca $2 \mathrm{p}$ spectra measured from the four Ca-containing $\mathrm{Tl}$ cuprate phases considered in this work are presented in Fig. 13. Each spectrum consists of two doublets separated by approximately $1 \mathrm{eV}$. Both of these components occur at significantly lower binding energies than the signal from surface contaminants ( $\mathrm{Ca} 2 \mathrm{p}_{32}$ binding energy near $347 \mathrm{eV}$ ), which is prominent prior to etching but is not detectable in the spectra in Fig. 13. These spectra are comparable to $\mathrm{Ca} 2 \mathrm{p}$ signals measured from other $\mathrm{Ca}$-containing cuprate superconductors (e.g. see the review in Ref. 48), and the two signals have been interpreted as originating from occupation of inequivalent lattice sites due to cation disorder, with the lower binding energy component corresponding to the site between $\mathrm{Cu}-\mathrm{O}$ planes. Significant cation disorder has in fact been detected in structure studies of $\mathrm{Tl}$ cuprates. ${ }^{52,53}$

$\mathrm{Ca}^{2+}$ ions are coordinated to eight $\mathrm{O}(1)$ atoms in double $\mathrm{Cu}-\mathrm{O}$ layer $\mathrm{Tl}$ cuprates, and to four $\mathrm{O}(\mathrm{l})$ and four $\mathrm{O}\left(\mathrm{l}^{\prime}\right)$ atoms in triple $\mathrm{Cu}-\mathrm{O}$ layer $\mathrm{Tl}$ cuprates. There is relatively little variation in the Ca $2 p_{3 / 2}$ binding energies between the various $\mathrm{Tl}$ cuprate phases, reflecting the similarity of the 
chemical environments since the average $\mathrm{Ca}-\mathrm{O}$ bond distance is $2.48 \pm 0.01 \AA$ for all of the $\mathrm{Ca}$ containing Tl cuprates studied here.

The $\mathrm{Ba}$ and $\mathrm{Ca}$ core level binding energies measured from the $\mathrm{Tl}$ cuprates are significantly lower than those measured from the corresponding metals, as is also the case for other cuprate superconductors ${ }^{48}$ and simpler alkaline earth compounds. ${ }^{49}$ The negative chemical shift observed in alkaline earth compounds is attributable to initial-state electrostatic effects, originating from the larger value of the Madelung energy relative to the ionization energy. ${ }^{49-51}$

\section{III. d. Valence band measurements}

Representative valence band spectra measured from the five $\mathrm{Tl}$ cuprate phases considered in this work are presented in Fig. 14. A closer view of the Fermi level region is shown in the inset of Fig. 14. The density of states at the Fermi level for the $T l$ cuprates is lower than is observed for other cuprate superconductors (e.g. see the review in Ref. 35), though Fermi edges are still apparent with varying degrees of clarity. The intensity of the feature near $4.5 \mathrm{eV}$ in the spectrum measured from (Tl,Bi)-1223 correlates with the level of Ag contaminant observed on the surface, and is thus an artifact of the annealing procedure.

The valence bands are comprised of states with primarily $\mathrm{Cu} 3 \mathrm{~d}, \mathrm{O} 2 \mathrm{p}$, and $\mathrm{Tl} 6 \mathrm{~s}$ and $5 \mathrm{~d}$ character. ${ }^{2,43,44}$ For the photon energy used in this work, the photoionization cross-sections are such that the $\mathrm{Cu}$ and $\mathrm{Tl}$ states are dominant in the spectra. ${ }^{54,55}$ The feature near $7 \mathrm{eV}$ consists of states with primarily $\mathrm{Tl} 6 \mathrm{~s}$ character. ${ }^{2.43,44,55}$ The variation in the relative intensity of this feature, evident in Fig. 14, is consistent with the variation in the $\mathrm{Tl} / \mathrm{Cu}$ ratios in the phases studied here. The main manifold in the $1-6 \mathrm{eV}$ region consists of states with primarily $\mathrm{Cu} 3 \mathrm{~d}$ character and exhibits relatively little difference for the various phases, reflecting the similarity in the calculated $\mathrm{Cu} 3 \mathrm{~d}$ partial densities of states. ${ }^{2,43,44}$ 


\section{Summary and Conclusions}

Photoemission measurements of $\mathrm{Tl}-2212, \mathrm{Tl}-2223$, and (Tl,Bi)-1223 have been presented which, together with previous measurements in this lab of Tl-2201 (Ref. 7) and Tl-1212 (Ref. 2), comprise a comprehensive data set for a comparative study of $\mathrm{Tl}$ cuprates with a range of chemical and electronic properties. Higher values of $T_{c}$ have been found to correlate with low values of $\mathrm{L} / \mathrm{T}_{\mathrm{m}}$ and high values of $E_{s}-E_{m}$ in the $\mathrm{Cu} 2 p$ spectra. Analysis of these spectra within a simple configuration interaction model suggests that higher values of $T_{c}$ are related to low values of the $O$ $2 p \rightarrow \mathrm{Cu} 3 \mathrm{~d}$ charge transfer energy, i.e. to more covalent $\mathrm{Cu}-\mathrm{O}$ bonding. In the $\mathrm{O} 1 \mathrm{~s}$ region, a smaller $\mathrm{Ba}-\mathrm{O}(1)$ bond length has been found to correlate with a lower binding energy for the signal associated with $\mathrm{Cu}-\mathrm{O}$ bonding, most likely resulting from the increased polarization screening by $\mathrm{Ba}^{2+}$ ions. For samples near optimum doping, maximum $\mathrm{T}_{\mathrm{c}}$ has been observed to occur when the $\mathrm{Tl} 4 \mathrm{f}_{72}$ binding energy is near $117.9 \mathrm{eV}$, which is near the middle of the range of values observed for $T l$ cuprates. Higher $T l 4 f_{7 n}$ binding energies, corresponding to formal oxidation states nearer $\mathrm{Tl}^{1+}$, have also been found to correlate with longer $\mathrm{Ba}-\mathrm{O}(3)$ bond lengths and higher binding energies of the $\mathrm{O}$ 1s signal associated with Th-O bonding. The alkaline earth core levels have been found to be similar to those measured from other cuprate superconductors. The measured valence bands have been found to be very similar to each other, consistent with the similarity in the $\mathrm{Cu} 3 \mathrm{~d}$ partial densities of states found in band structure calculations, with the exception of a feature near 7 $\mathrm{eV}$ corresponding to states with predominant $\mathrm{Tl} 6 \mathrm{~s}$ character, the relative intensity of which varies consistently with the varying TV/Cu ratio in the phases studied.

\section{Acknowledgments}

Part of the work described in this paper was performed by the Center for Space Microelectronics Technology, Jet Propulsion Laboratory, California Institute of Technology, and was sponsored by the National Aeronautics and Space Administration, Office of Space Science. Part of this work was performed at Sandia National Laboratories, Albuquerque, NM, and supported by the U. S. Department of Energy, Office of Basic Energy Sciences under contract no. DE-ACO4-94AL85000. The work performed at SUNY at Buffalo is supported partially by the New York State Energy Research and Development Authority and Oak Ridge National Laboratory. 


\section{References}

1. D. L. Novikov and A. J. Freeman, in Recent Advances in High Temperature Superconductivity, edited by J. Klamut, B. W. Veal, B. M. Dabrowski, P. W. Klamut, and M. Kazimierski, Lecture Notes in Physics, Vol. 475 (Springer-Verlag, New York, 1996).

2. R. P. Vasquez, D. L. Novikov, A. J. Freeman, and M. P. Siegal, Phys. Rev. B 55, 14623 (1997).

3. M. P. Siegal, E. L. Venturini, P. P. Newcomer, B. Morosin, D. L. Overmyer, F. Dominguez, and R. Dunn, Appl. Phys. Lett. 67, 3966 (1995).

4. N. H. Hur, N. H. Kim, K. W. Lee, K. H. Yoo, Y. K. Park, and J. C. Park, Physica C 234, 19 (1994).

5. N. H. Hur, M. Paranthaman, J. R. Thompson, and D. K. Christen, Physica C 268, 266 (1996).

6. S. Nakajima, M. Kikuchi, Y. Syono, N. Kobayashi, and Y. Muto, Physica C 168, 57 (1989).

7. R. P. Vasquez, Z. F. Ren, and J. H. Wang, Phys. Rev. B 54, 6115 (1996).

8. Y. Shimakawa, Y. Kubo, T. Manako, H. Igarashi, F. Izumi, and H. Asano, Phys. Rev. B 42, 10165 (1990).

9. B. Morosin, D. S. Ginley, P. F. Hlava, M. J. Carr, R. J. Baughman, J. E. Schirber, E. L. Venturini, and J. F. Kwak, Physica C 152, 413 (1988).

10. D. E. Cox, C. C. Torardi, M. A. Subramanian, J. Gopalakrishnan, and A. W. Sleight, Phys. Rev. B 38, 6624 (1988).

11. M. A. Subramanian, J. B. Parise, J. C. Calabrese, C. C. Torardi, J. Gopalakrishnan, and A. W. Sleight, J. Solid State Chem. 77, 192 (1988).

12. N. H. Hur, B. C. Chakoumakos, M. Paranthaman, J. R. Thompson, and D. K. Christen, Physica C 253, 109 (1995). 
13. F. Parmigiani, L. E. Depero, T. Minerva, and J. B. Torrance, J. Electron Spectrosc. Relat. Phenom. 58, 315 (1992).

14. G. van der Laan, C. Westra, C. Haas, and G. A. Sawatzky, Phys. Rev. B 23, 4369 (1981).

15. D. D. Sarma and S. G. Ovchinnikov, Phys. Rev. B 42, 6817 (1990).

16. J.-J. Yeh, I. Lindau, J.-Z. Sun, K. Char, N. Missert, A. Kapitulnick, T. H. Geballe, and M. R. Beasley, Phys. Rev. B 42, 8044 (1990).

17. F. Parmigiani and L. Sangaletti, J. Electron Spectrosc. Relat. Phenom. 66, 223 (1994), and references therein.

18. A. K. Santra, D. D. Sarma, and C. N. R. Rao, Phys. Rev. B 43, 5612 (1991).

19. C. S. Gopinath, S. Subramanian, M. Paranthaman, and A. M. Hermann, J. Solid State Chem. 109, 211 (1994).

20. C. N. R. Rao, G. R. Rao, M. K. Rajumon, and D. D. Sarma, Phys. Rev. B 42, 1026 (1990).

21. C. S. Gopinath, S. Subramanian, M. Paranthaman, and A. M. Hermann, Phys. Rev. B 48, 15999 (1993).

22. T. Suzuki, M. Nagoshi, Y. Fukuda, S. Nakajima, M. Kikuchi, Y. Syono, and M. Tachiki, Physica C 162-164, 1387 (1989).

23. Y. Fukuda, T. Suzuki, and M. Nagoshi, in Thallium-Based High Temperature Superconductors, Eds. A. M. Hermann and J. V. Yakhmi (Marcel Dekker, Inc., New York, 1994), Chapter 24, pp. 511-522.

24. H. M. Meyer III, T. J. Wagener, J. H. Weaver, and D. S. Ginley, Phys. Rev. B 39, 7343 (1989).

25. T. Suzuki, M. Nagoshi, Y. Fukuda, Y. Syono, M. Kikuchi, N. Kobayashi, and M. Tachiki, Phys. Rev. B 40, 5184 (1989).

26. T. Suzuki, M. Nagoshi, Y. Fukuda, S. Nakajima, M. Kikuchi, Y. Syono, and M. Tachiki, Supercond. Sci. Technol. 7, 817 (1994). 
27. M. P. Siegal, E. L. Venturini, B. Morosin, and T. L. Aselage, J. Materials Research 12, 2825 (1997).

28. Z. F. Ren, C. A. Wang, and J. H. Wang, Appl. Phys. Lett. 65, 237 (1994).

29. Z. F. Ren, C. A. Wang, J. H. Wang, D. J. Miller, D. K. Christen, J. D. Hettinger, and K. E. Gray, Physica C 258, 129 (1995).

30. R. P. Vasquez, M. Rupp, A. Gupta, and C. C. Tsuei, Phys. Rev. B 51, 15657 (1995).

31. R. P. Vasquez and R. M. Housley, Physica C 175, 233 (1991).

32. R. P. Vasquez, M. C. Foote, L. Bajuk, and B. D. Hunt, J. Electron Spectrosc. Relat. Phenom. 57, 317 (1991).

33. R. P. Vasquez and W. L. Olson, Physica C 177, 223 (1991).

34. R. P. Vasquez, B. D. Hunt, M. C. Foote, L. J. Bajuk, and W. L. Olson, Physica C 190, 249 (1992).

35. R. P. Vasquez, J. Electron Spectrosc. Relat. Phenom. 66, 209 (1994), and references therein.

36. P. G. Radaelli, J. L. Wagner, B. A. Hunter, M. A. Beno, G. S. Knapp, J. D. Jorgensen, and D. G. Hinks, Physica C 216, 29 (1993).

37. I. M. Boswarva, Phys. Rev. B 1, 1698 (1970).

38. S. Larsson, Chem. Phys. Lett. 40, 362 (1976).

39. T. Suzuki, M. Nagoshi, Y. Fukuda, K. Oh-ishi, Y. Syono, and M. Tachiki, Phys. Rev. B 42, 4263 (1990).

40. P. Niedermann, A. P. Grande, J. K. Grepstad, J.-M. Triscone, M. G. Karkut, O. Brunner, L. Antognazza, W. Sadowski, H. J. Scheel, and O. Fischer, J. Appl. Phys. 68, 1777 (1990).

41. J. M. Tranquada, S. M. Heald, W. Kunnmann, A. R. Moodenbaugh, S. L. Qiu, Y. Xu, and P. K. Davies, Phys. Rev. B 44, 5176 (1991).

42. T. R. Cummins and R. G. Egdell, Phys. Rev. B 48, 6556 (1993).

43. J. Yu, S. Massidda, and A. J. Freeman, Physica C 152, 273 (1988). 
44. D. R. Hamann and L. F. Mattheiss, Phys. Rev. B 38, 5138 (1988).

45. K. S. Kim, T. J. O'Leary, and N. Winograd, Anal. Chem. 45, 2214 (1973).

46. G. E. McGuire, G. K. Schweitzer, and T. A. Carlson, Inorg. Chem. 12, 2450 (1973).

47. B. Morosin and E. L. Venturini, Phys. Rev. B 46, 510 (1992).

48. R. P. Vasquez, J. Electron Spectrosc. Relat. Phenom. 66, 241 (1994), and references therein.

49. R. P. Vasquez, J. Electron Spectrosc. Relat. Phenom. 56, 217 (1991).

50. P. S. Bagus, G. Pacchioni, C. Sousa, T. Minerva, and F. Parmigiani, Chem. Phys. Lett. 196, 641 (1992).

51. C. Sousa, T. Minerva, G. Pacchioni, P. S. Bagus, and F. Parmigiani, J. Electron Spectrosc. Relat. Phenom. 63, 189 (1993).

52. B. Morosin, R. J. Baughman, , D. S. Ginley, J. E. Schirber, and E. L. Venturini, Physica C 161, 115 (1990).

53. B. Morosin, D. S. Ginley, E. L. Venturini, R. J. Baughman, and C. P. Tigges, Physica C 172, 413 (1991).

54. J. J. Yeh and I. Lindau, At. Data Nucl. Data Tables 32, 1 (1985).

55. P. Marksteiner, J. Yu, S. Massidda, A. J. Freeman, J. Redinger, and P. Weinberger, Phys. Rev. B 39, 2894 (1989). 
Table I. Summary of core level binding energies and peak full widths at half maximum (in parentheses) for (T1,Bi)-1223, Tl-2212 and Tl-2223 epitaxial films measured in this work, together with previously reported measurements from this lab for epitaxial tilms of Tl-2201, Tl-1212, and $\mathrm{Hg}-1212$.

\begin{tabular}{|c|c|c|c|c|c|c|c|}
\hline Material & $\mathbf{T}_{c-}$ & $\mathrm{Tl} 4 \mathrm{f}_{7 / 2}$ & $\mathrm{Ba} 3 \mathrm{~d}_{5 / 2}$ & $\mathrm{Ba} 4 d_{5 / 2}$ & $\mathrm{Ca} 2 \mathbf{p}_{3 / 2}$ & Q $1 \mathrm{~s}$ & Source \\
\hline \multirow[t]{2}{*}{ Tl-1212 } & 87.5 & $117.75(1.42)$ & $778.09(1.51)$ & $87.67(1.20)$ & $344.42 \& 345.51$ & $528.08 \& 528.58$ & Ref. 2 \\
\hline & 86.4 & $117.83(1.42)$ & $778.13(1.50)$ & $87.71(1.14)$ & $344.45 \& 345.65$ & $527.99 \& 528.55$ & Ref. 2 \\
\hline (overdoped) & 74.5 & $117.66(1.40)$ & $777.99(1.48)$ & $87.56(1.18)$ & $344.40 \& 345.49$ & $527.93 \& 528.55$ & Ref. 2 \\
\hline \multirow[t]{5}{*}{$(\mathrm{Tl}, \mathrm{Bi})-1223$} & 106.1 & $117.83(1.33)$ & $777.94(1.44)$ & $87.56(1.11)$ & $344.59 \& 345.73$ & $527.98 \& 528.51$ & This work \\
\hline & 105.3 & $117.81(1.32)$ & $777.92(1.45)$ & $87.55(1.05)$ & $344.61 \& 345.70$ & $528.02 \& 528.61$ & This work \\
\hline & 105.2 & $117.83(1.34)$ & $777.94(1.48)$ & $87.57(1.05)$ & $344.64 \& 345.72$ & $528.01 \& 528.62$ & This work \\
\hline & 104.7 & $117.79(1.29)$ & $777.92(1.47)$ & $87.56(1.08)$ & $344.59 \& 345.37$ & $528.01 \& 528.63$ & This work \\
\hline & 103.2 & $117.82(1.30)$ & $777.97(1.48)$ & $87.57(1.07)$ & $344.65 \& 345.53$ & $528.01 \& 528.56$ & This work \\
\hline \multirow[t]{2}{*}{ T1-2201 } & 63 & $118.12(1.25)$ & $777.89(1.44)$ & $87.50(1.05)$ & none & $527.50 \& 528.95$ & Ref. 7 \\
\hline & 53 & $118.20(1.27)$ & $778.00(1.51)$ & $87.61(1.20)$ & none & $527.57 \& 528.97$ & Ref. 7 \\
\hline \multirow{2}{*}{$\begin{array}{l}\text { (overdoped) } \\
\text { (overdoped) }\end{array}$} & 11 & $117.88(1.23)$ & $777.77(1.49)$ & $87.35(1.03)$ & none & $527.39 \& 528.63$ & Ref. 7 \\
\hline & 11 & $117.86(1.19)$ & $777.76(1.45)$ & $87.36(1.04)$ & none & $527.39 \& 528.58$ & Ref. 7 \\
\hline \multirow[t]{2}{*}{$\mathrm{Tl}-2212$} & 104.2 & $117.98(1.27)$ & $778.26(1.47)$ & $87.89(1.11)$ & $344.57 \& 345.67$ & $527.97 \& 528.75$ & This work \\
\hline & 101.8 & $118.03(1.27)$ & $778.34(1.48)$ & $87.96(1.17)$ & $344.64 \& 345.89$ & $527.95 \& 528.80$ & This work \\
\hline \multirow[t]{2}{*}{$\mathrm{Tl}-2223$} & 111.4 & $117.84(1.23)$ & $778.05(1.43)$ & $87.67(1.11)$ & $344.61 \& 345.78$ & $527.94 \& 528.63$ & This work \\
\hline & 109 & $117.91(1.21)$ & $778.10(1.43)$ & $87.71(1.06)$ & $344.58 \& 345.80$ & $527.96 \& 528.73$ & This work \\
\hline \multirow[t]{2}{*}{$\mathrm{Hg}-1212$} & 117 & none & $778.21(1.44)$ & $87.83(1.13)$ & $344.39 \& 345.58$ & $527.82 \& 528.70$ & Ref. 30 \\
\hline & 116 & none & $778.28(1.52)$ & $87.96(1.15)$ & $344.47 \& 345.56$ & $527.86 \& 528.69$ & Ref. 30 \\
\hline
\end{tabular}


Table II. Summary of the $\mathrm{Cu} 2 \mathrm{p}_{3 / 2}$ main peak binding energies $\left(\mathrm{E}_{\mathrm{m}}=\right.$ centroid position), peak full widths at half maximum (FWHM), satellite - main peak intensity ratios $\left(\mathrm{I}_{\mathrm{s}} \mathrm{I}_{\mathrm{m}}\right)$, and satellite - main peak energy separations $\left(\mathrm{E}_{\mathrm{s}}-\mathrm{E}_{\mathrm{m}}\right)$ for epitaxial films of the $T 1$ and rare earth cuprate phases measured in this work, together with previously reported measurements from this lab.

\begin{tabular}{|c|c|c|c|c|c|c|}
\hline Material & $I_{c}$ & $\underline{\mathbf{E}}_{\mathrm{m}}$ & FWHM & $\underline{\mathbf{I}}_{s} \mathbf{I}_{\mathrm{m}}$ & $\mathbf{E}_{s}-\mathbf{E}_{m}$ & Source \\
\hline \multirow[t]{3}{*}{ Tl-1212 } & 87.5 & 933.53 & 3.39 & 0.419 & 8.47 & Ref. 2 \\
\hline & 86.4 & 933.49 & 3.44 & 0.418 & 8.47 & Ref. 2 \\
\hline & 74.5 (overdoped) & 933.51 & 3.49 & 0.425 & 8.46 & Ref. 2 \\
\hline \multirow[t]{5}{*}{$(\mathrm{Tl}, \mathrm{Bi})-1223$} & 106.1 & 933.45 & 3.71 & 0.374 & 8.55 & This work \\
\hline & 105.3 & 933.42 & 3.68 & 0.372 & 8.54 & This work \\
\hline & 105.2 & 933.42 & 3.64 & 0.374 & 8.51 & This work \\
\hline & 104.7 & 933.48 & 3.39 & 0.379 & 8.44 & This work \\
\hline & 103.2 & 933.47 & 3.49 & 0.376 & 8.47 & This work \\
\hline \multirow[t]{4}{*}{ Tl-2201 } & 63 & 933.34 & 3.35 & 0.450 & 8.46 & Ref. 7 \\
\hline & 53 & 933.33 & 3.31 & 0.421 & 8.54 & Ref. 7 \\
\hline & 11 (overdoped) & 933.36 & 3.39 & 0.476 & 8.49 & Ref. 7 \\
\hline & 11 (overdoped) & 933.33 & 3.35 & 0.446 & 8.41 & Ref. 7 \\
\hline \multirow[t]{2}{*}{$\mathrm{Tl}-2212$} & 104.2 & 933.45 & 3.50 & 0.397 & 8.44 & This work \\
\hline & 101.8 & 933.56 & 3.49 & 0.413 & 8.34 & This work \\
\hline \multirow[t]{2}{*}{$\mathrm{Tl}-2223$} & 111.4 & 933.41 & 3.53 & 0.391 & 8.46 & This work \\
\hline & 109 & 933.38 & 3.45 & 0.376 & 8.52 & This work \\
\hline \multirow[t]{2}{*}{$\mathrm{Hg}-1212$} & 117 & 933.41 & 3.72 & 0.362 & 8.63 & Ref. 30 \\
\hline & 116 & 933.50 & 3.72 & 0.371 & 8.55 & Ref. 30 \\
\hline $\mathrm{Bi}-2212$ & 85 & 933.48 & 3.50 & 0.413 & 8.58 & Ref. 31 \\
\hline \multirow[t]{2}{*}{$Y-123$} & 89 & 933.39 & 3.50 & 0.407 & 8.41 & Ref. 32 \\
\hline & 0 (underdoped) & 933.47 & 2.40 & 0.289 & 8.78 & Ref. 32 \\
\hline $\mathrm{La}_{2} \mathrm{CuO}_{4}$ & 0 & 933.51 & 2.93 & 0.411 & 8.73 & This work \\
\hline $\mathrm{Nd}_{2} \mathrm{CuO}_{4}$ & 0 & 933.75 & 3.39 & 0.363 & 9.01 & This work \\
\hline $\mathrm{Gd}_{2} \mathrm{CuO}_{4}$ & 0 & 934.19 & 3.15 & 0.388 & 8.73 & This work \\
\hline
\end{tabular}




\section{Figure Captions}

1. Representative $\mathrm{O}$ ls spectra measured from the five $\mathrm{Tl}$ cuprate phases considered in this work.

2. Second derivatives of the spectra from Fig. 1, showing more clearly the two components of the spectra associated with $\mathrm{Cu}-\mathrm{O}$ and $\mathrm{Tl}-\mathrm{O}$ bonding.

3. Ba-O(1) bond length vs. $\mathrm{O}$ 1s binding energy, using the data from Table I for those samples near optimum doping and crystal structure determinations from the literature (Refs. 8-12,36). A linear least squares fit is also shown as a guide to the eye.

4. Representative $\mathrm{Cu} 2 \mathrm{p}_{32}$ spectra measured from the five $\mathrm{Tl}$ cuprate phases considered in this work.

5. $I_{s} / I_{m} v s . T_{c}$, using the data from Table $I I$ for those samples near optimum doping. A linear least squares fit is also shown as a guide to the eye.

6. Plots of (a) $I_{m} I_{m}$ and (b) $E_{s}-E_{m}$ vs. $T$ and $\Delta$. The curves are the calculated values of $I_{s} / I_{m}$ and $E_{s}-E_{m}$ as (top curve in each panel) $T$ is varied for fixed $\Delta(0.75 \mathrm{eV})$ and $U(7.8 \mathrm{eV})$, and (bottom curve in each panel) $\Delta$ is varied for fixed $\mathrm{T}(2.4 \mathrm{eV})$ and $\mathrm{U}(7.8 \mathrm{eV})$. The data points are the experimental values of $\mathrm{Is}_{\mathrm{m}} / \mathrm{I}_{\mathrm{m}}$ and $\mathrm{E}_{\mathrm{s}}-\mathrm{E}_{\mathrm{m}}$ vs. the values of $\mathrm{T}$ or $\Delta$ obtained from the individual spectra.

7. Representative $\mathrm{Tl} 4 \mathrm{f}$ spectra measured from the five $\mathrm{Tl}$ cuprate phases considered in this work.

8. $\quad \mathrm{Tl}_{4 \mathrm{f}_{72}}$ vs. $\mathrm{O}(2,3) \mathrm{O} 1 \mathrm{~s}$ binding energies. A linear least squares fit is also shown as a guide to the eye.

9. $\quad \mathrm{Tl}_{4} \mathrm{f}_{72}$ binding energy vs. $\mathrm{T}_{\mathrm{c}}$ for samples near optimum doping. A quadratic least squares fit is also shown as a guide to the eye.

10. $\mathrm{Tl} 4 \mathrm{f}_{72}$ binding energy vs. $\mathrm{Ba}-\mathrm{O}(3)$ bond length for samples near optimum doping. A linear least squares fit is also shown as a guide to the eye. 
11. Representative $\mathrm{Ba} 4 \mathrm{~d}$ spectra measured from the five $\mathrm{Tl}$ cuprate phases considered in this work.

12. $\mathrm{Ba} 4 \mathrm{~d}_{52}$ binding energy vs. the average $\mathrm{Ba}-\mathrm{O}$ bond length, $\langle\mathrm{R}(\mathrm{Ba}-\mathrm{O})\rangle$. The line is a guide to the eye.

13. Representative $\mathrm{Ca} 2 \mathrm{p}$ spectra measured from the four Ca-containing $\mathrm{Tl}$ cuprate phases considered in this work.

14. Representative valence band spectra measured from the five $T$ cuprate phases considered in this work. Inset: Fermi level region. 


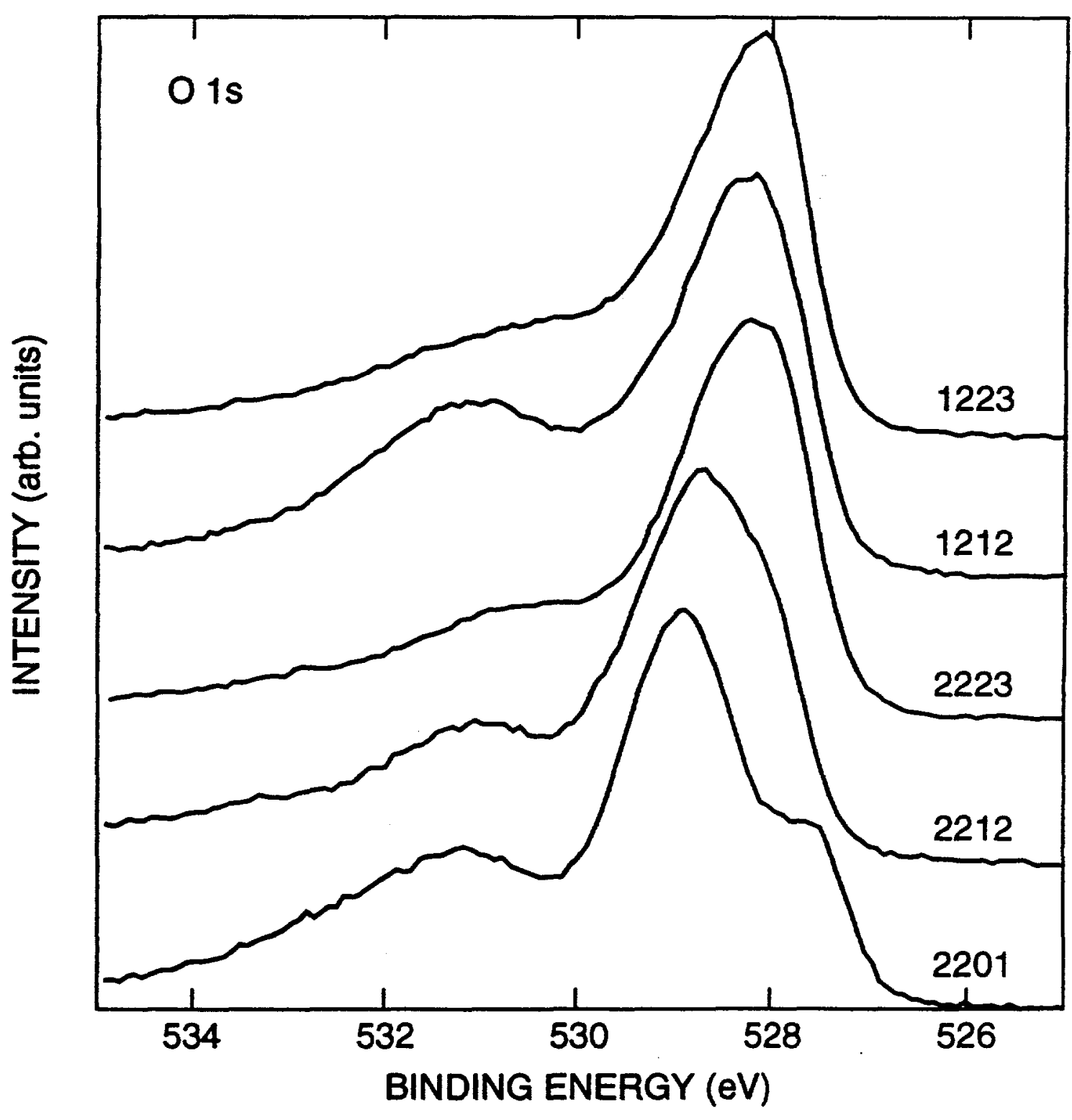




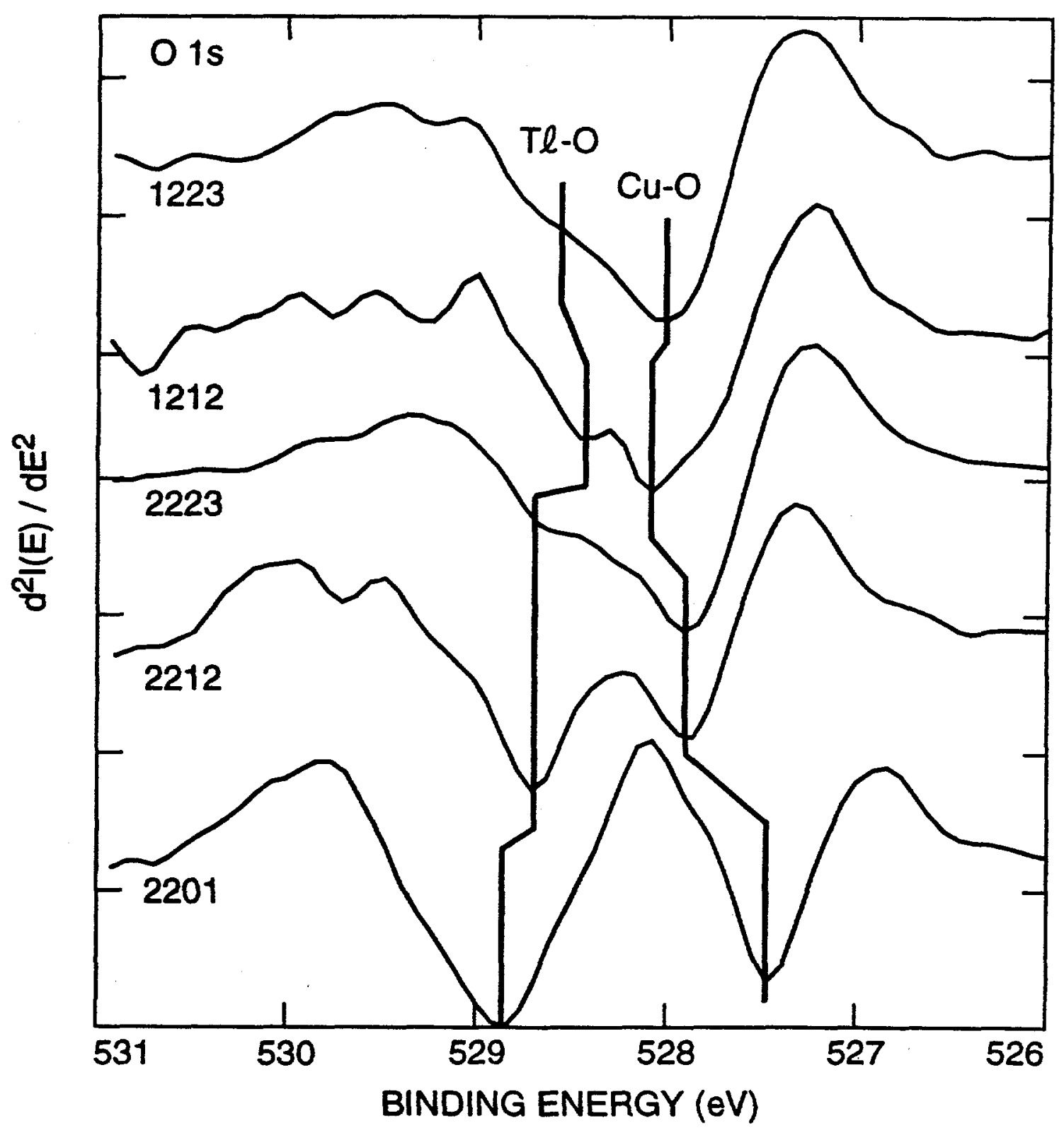




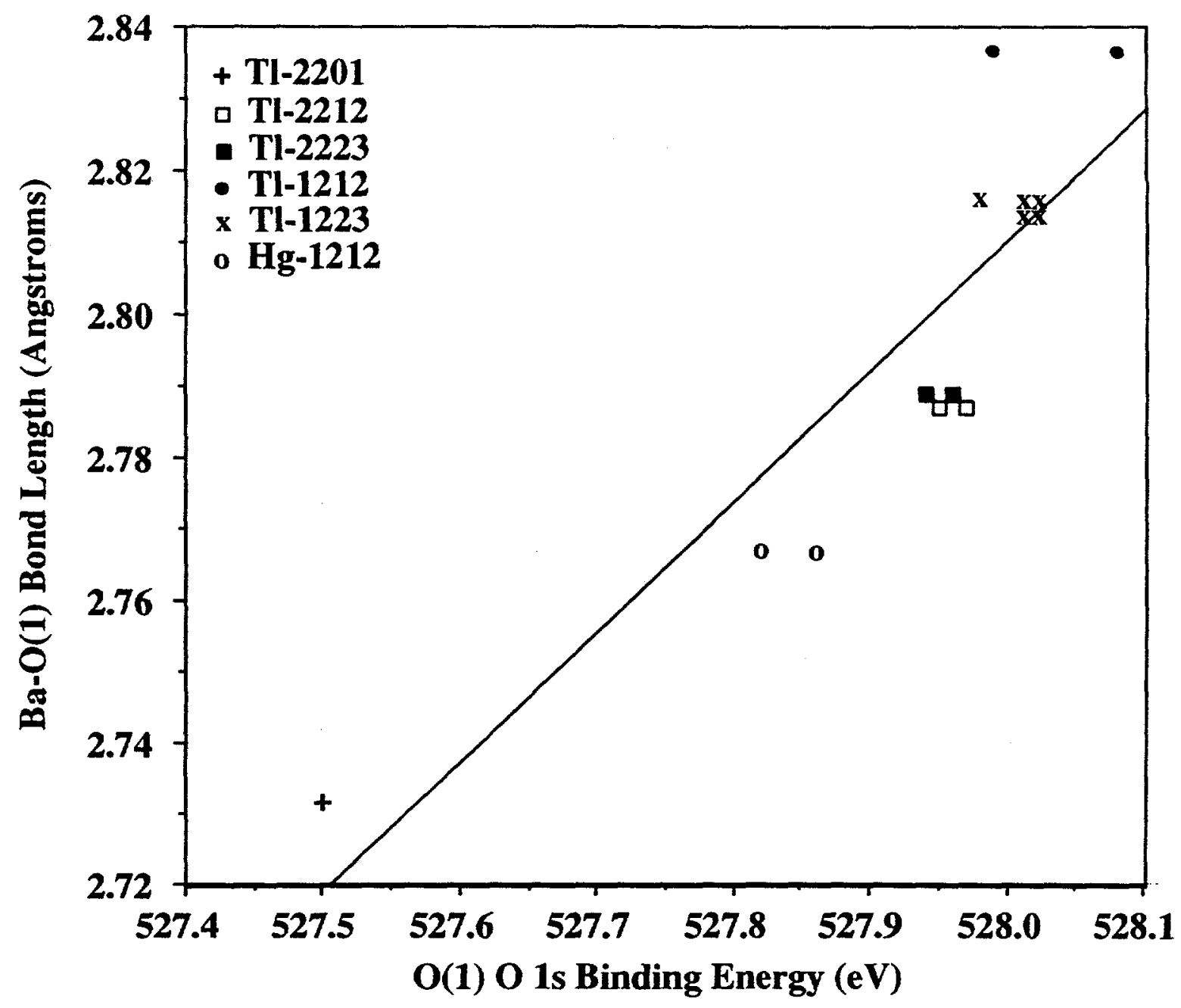




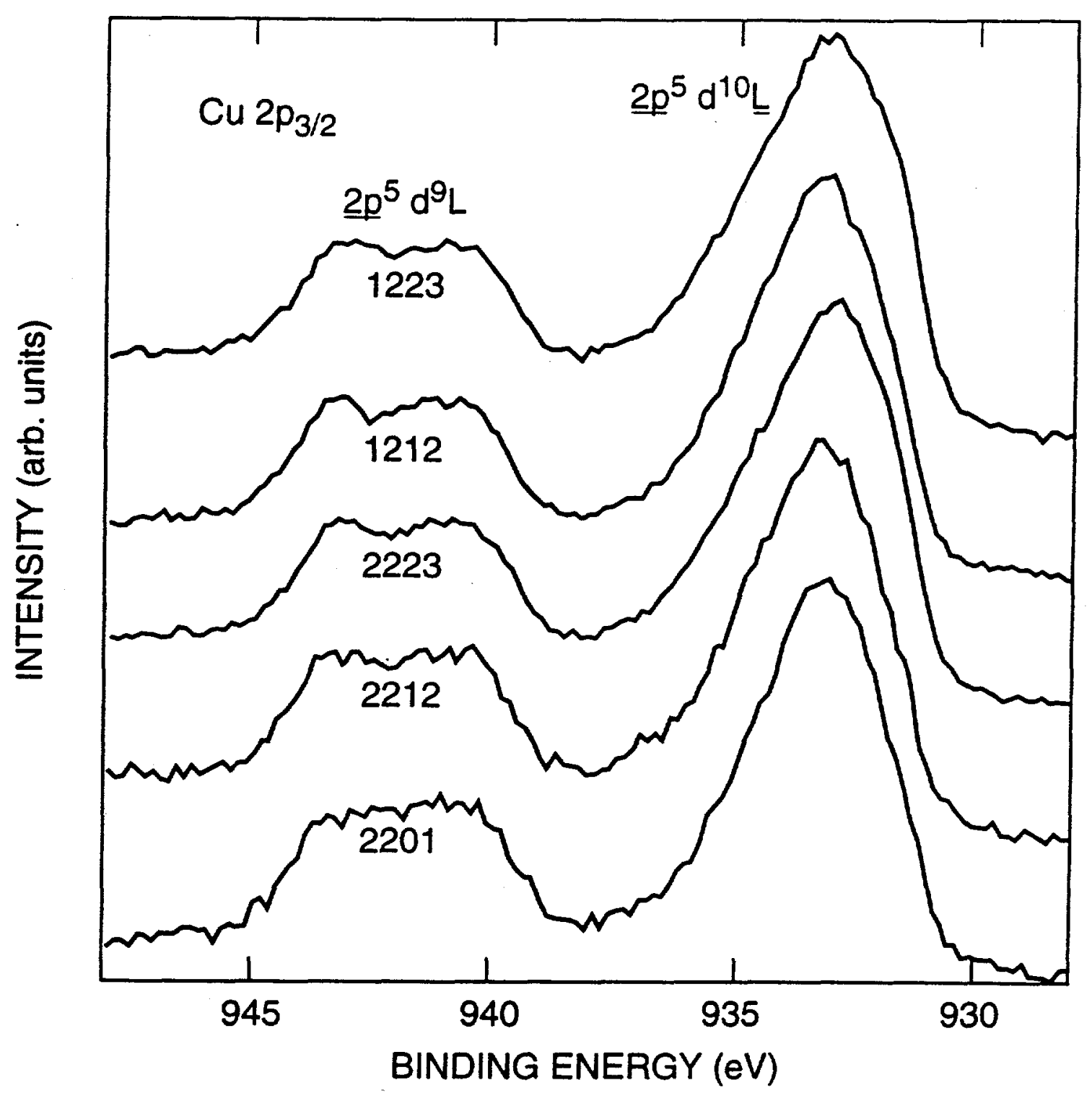




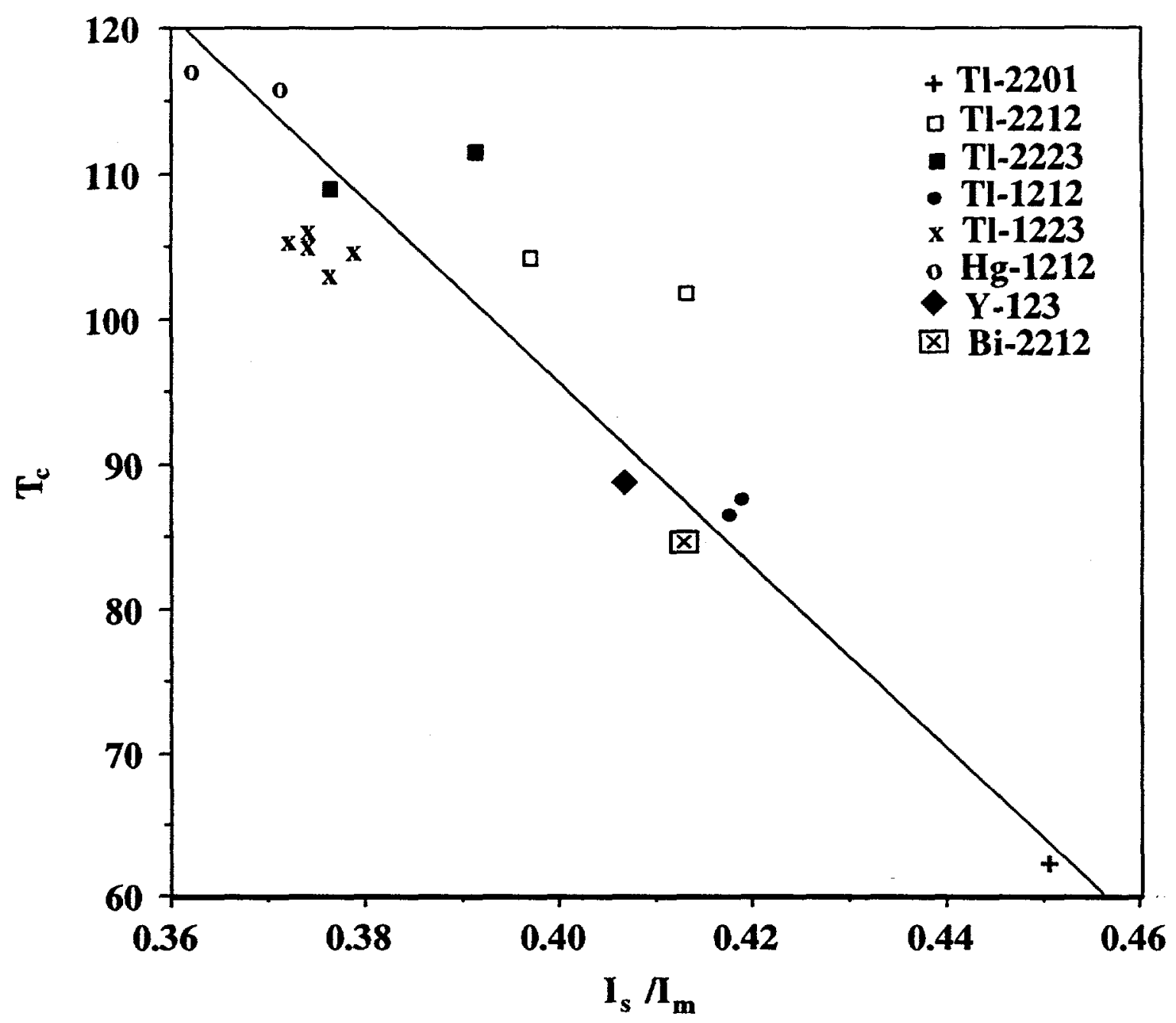




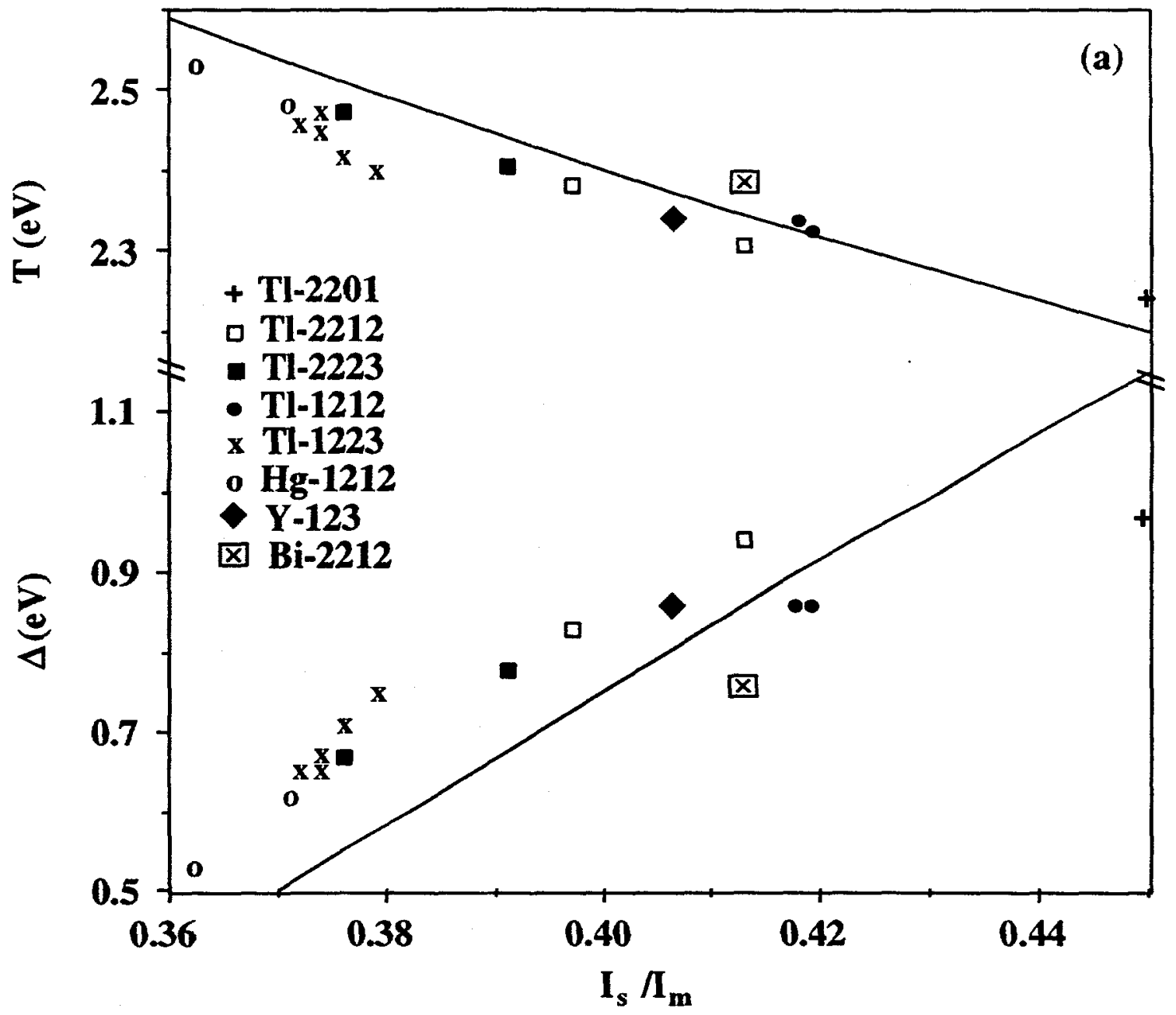




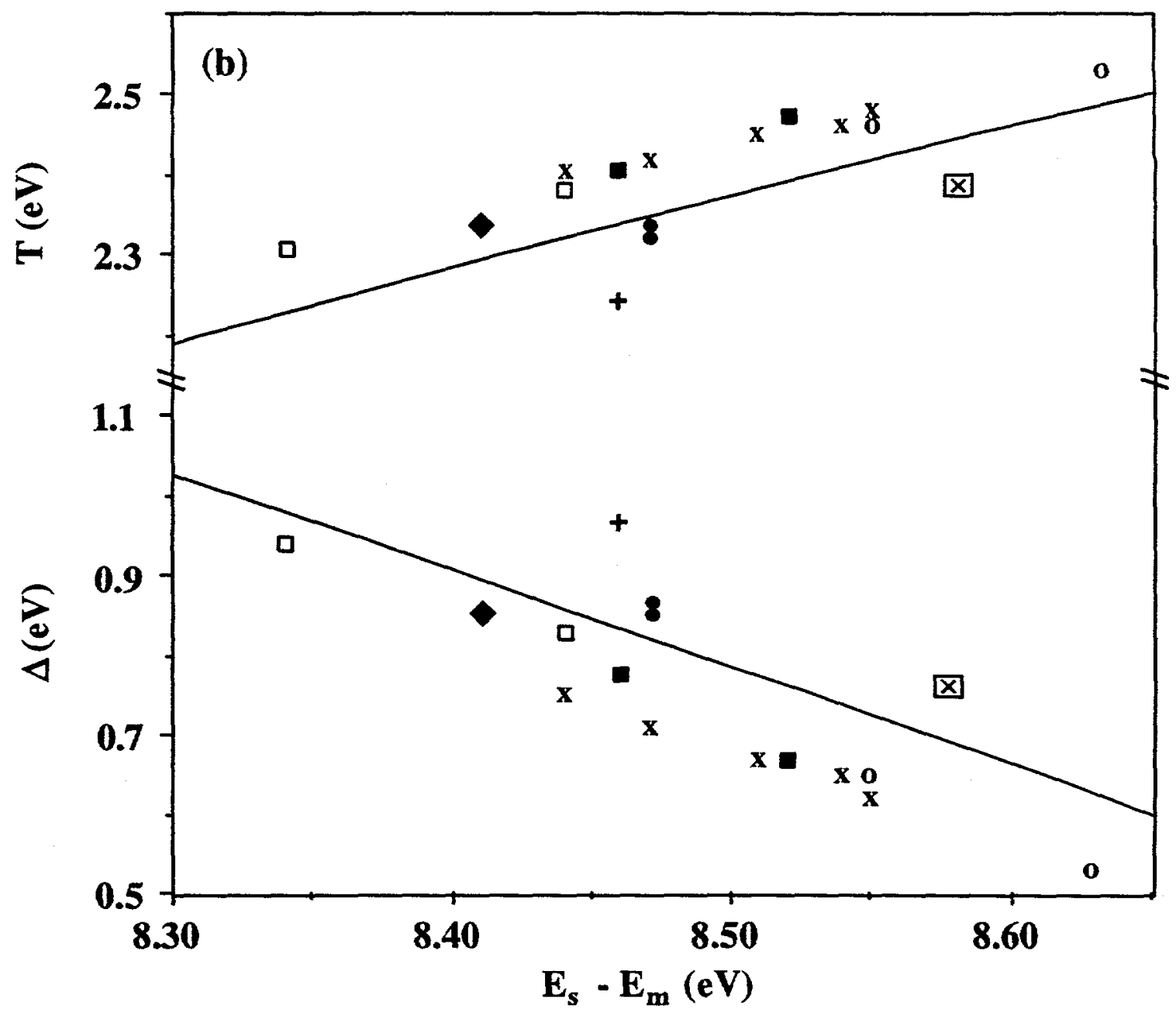




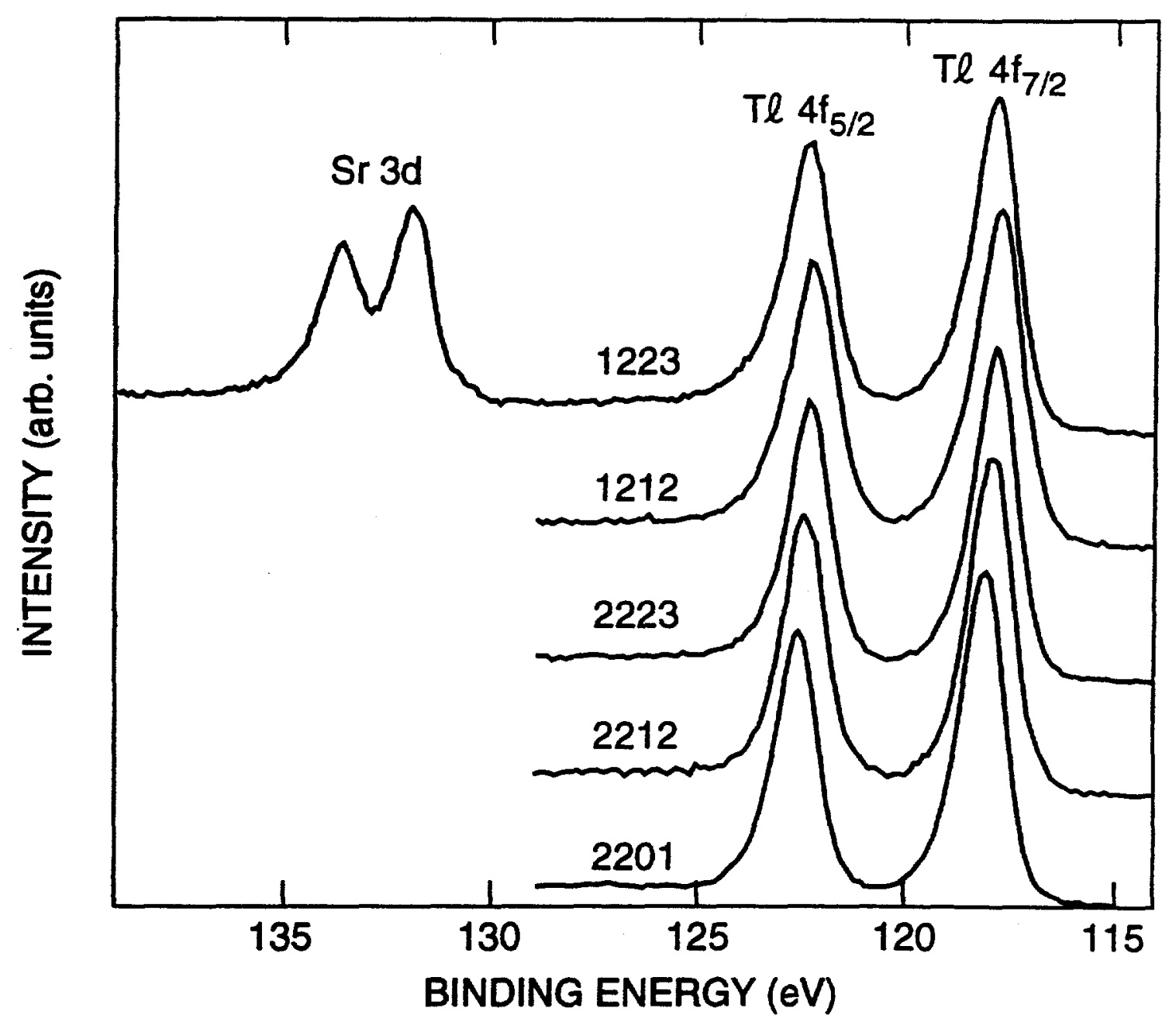




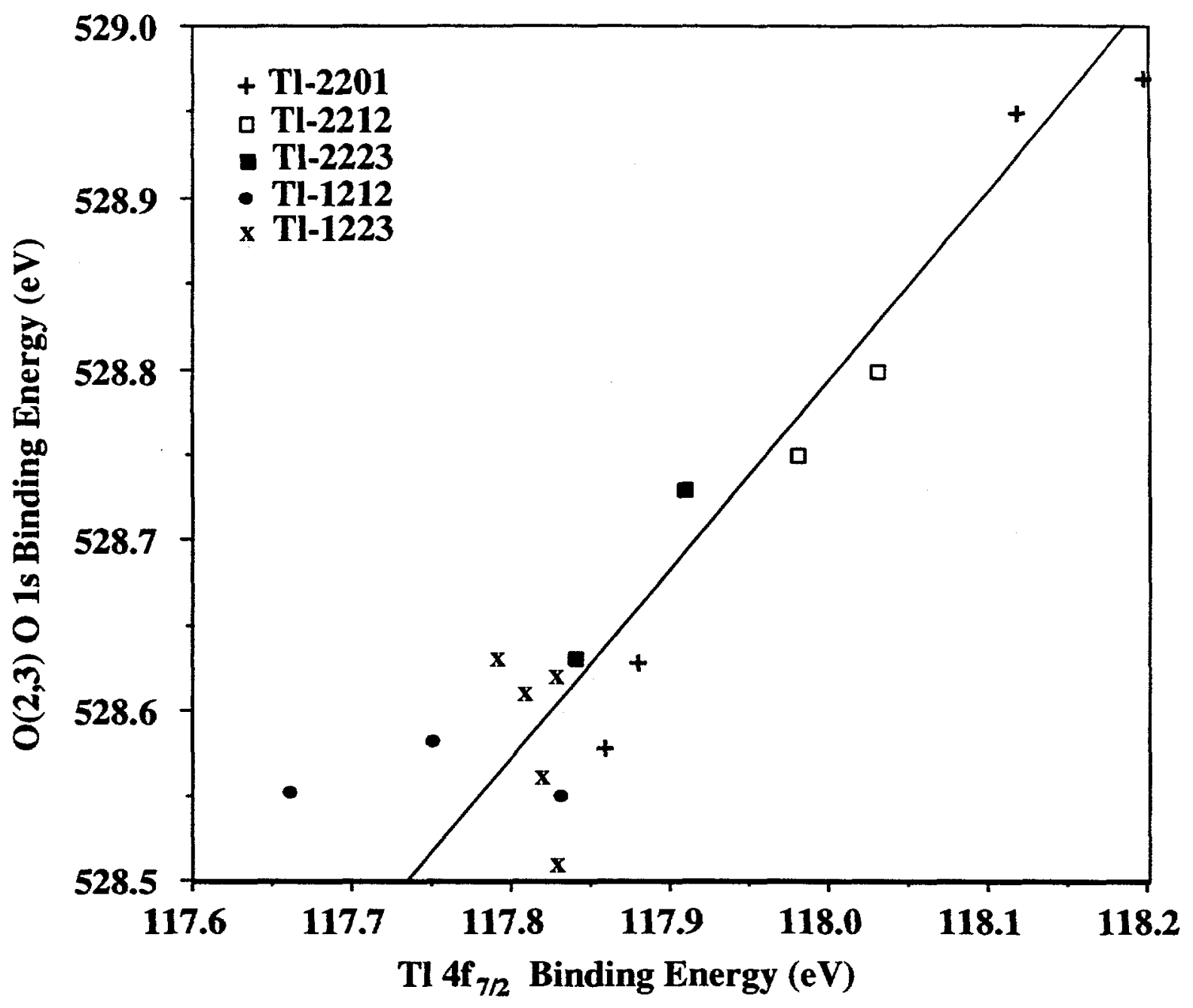




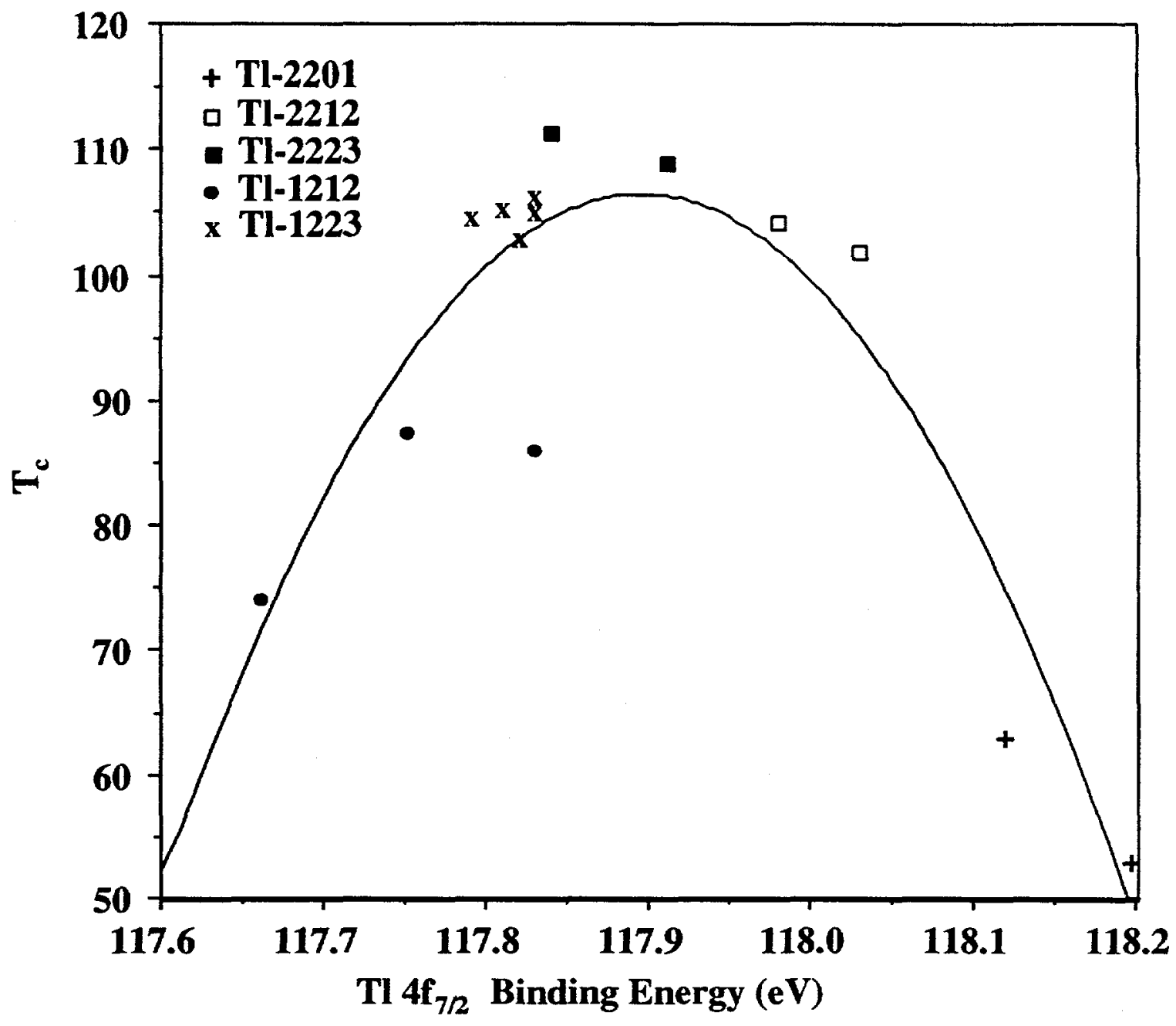




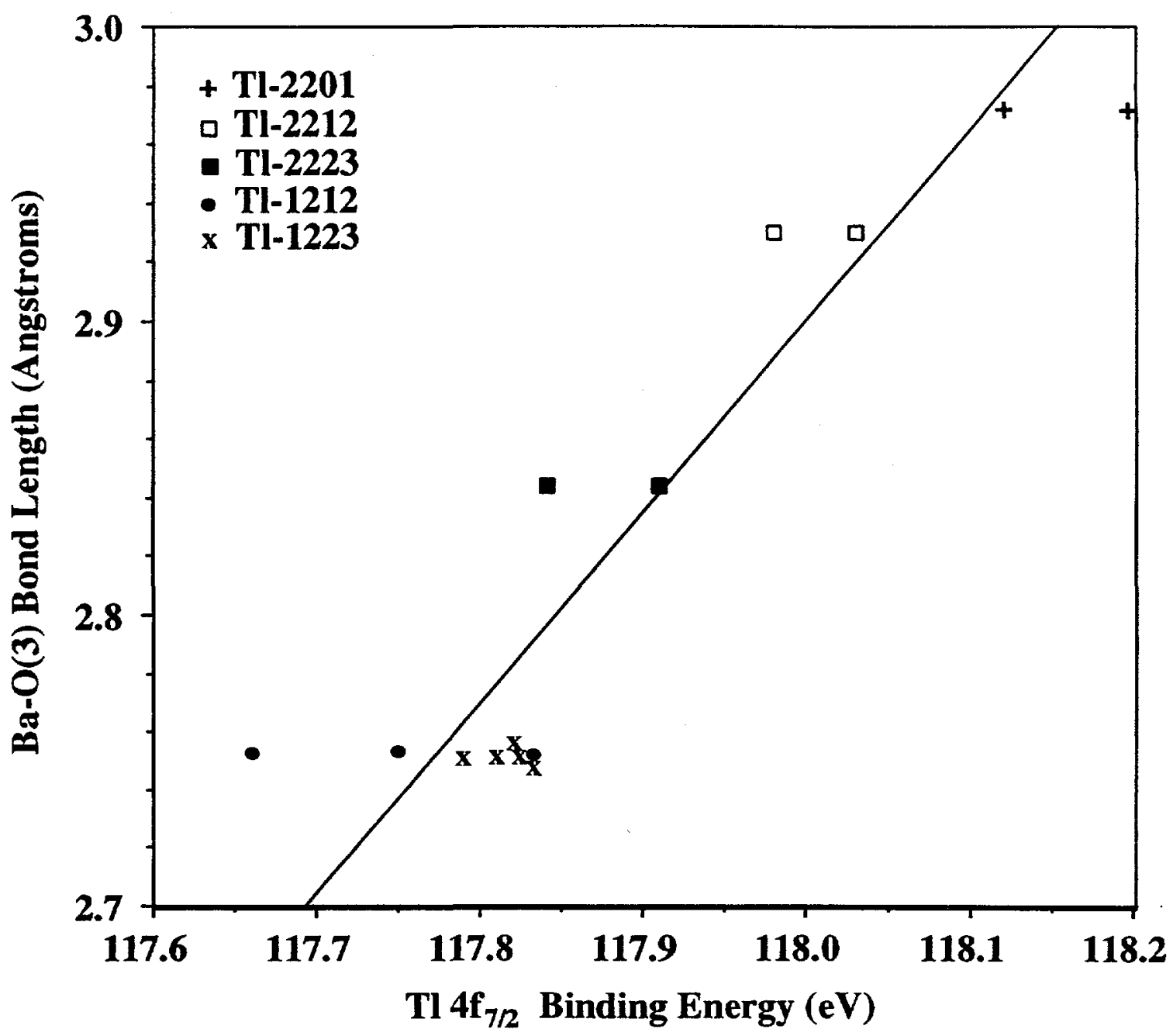




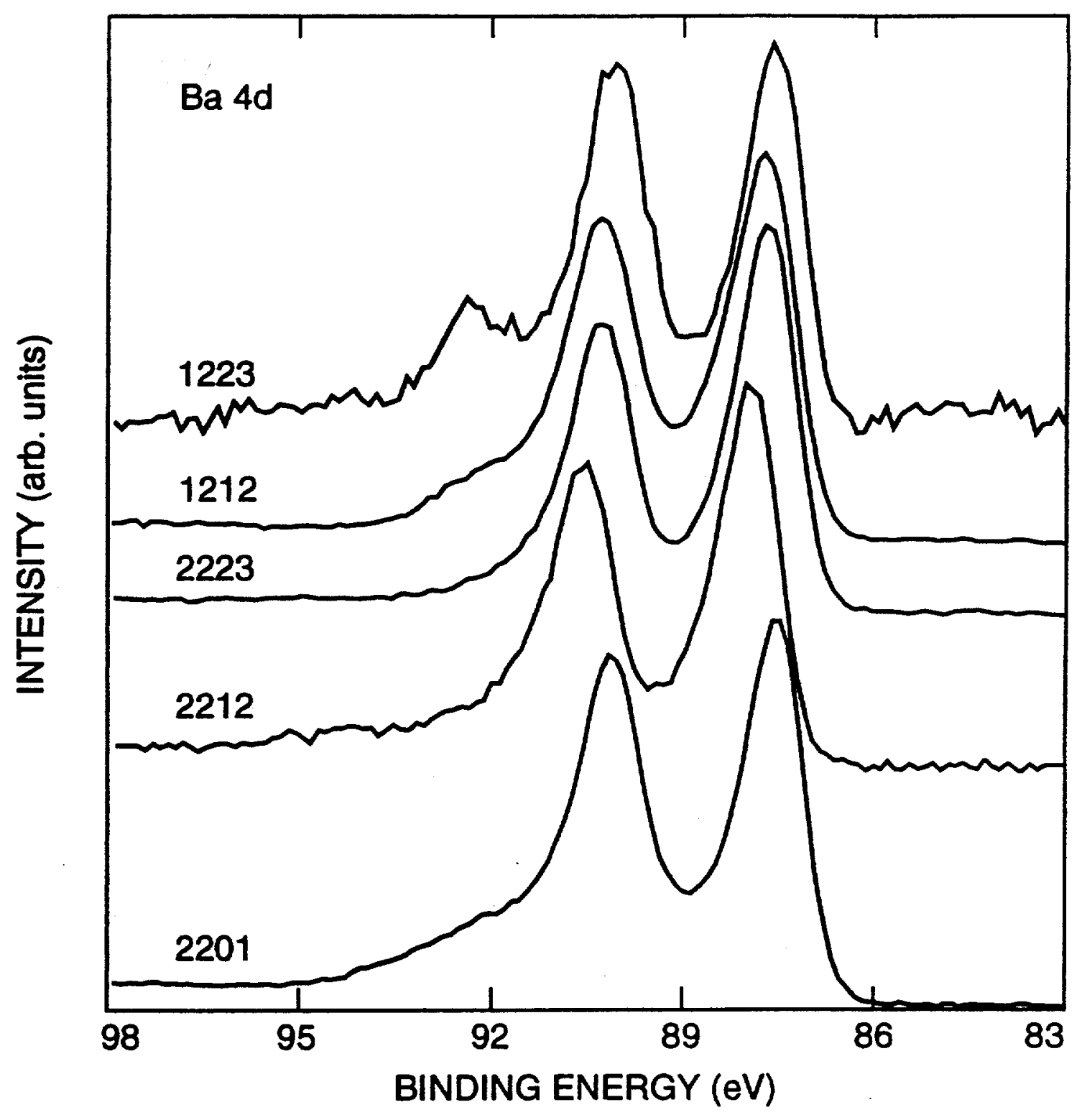




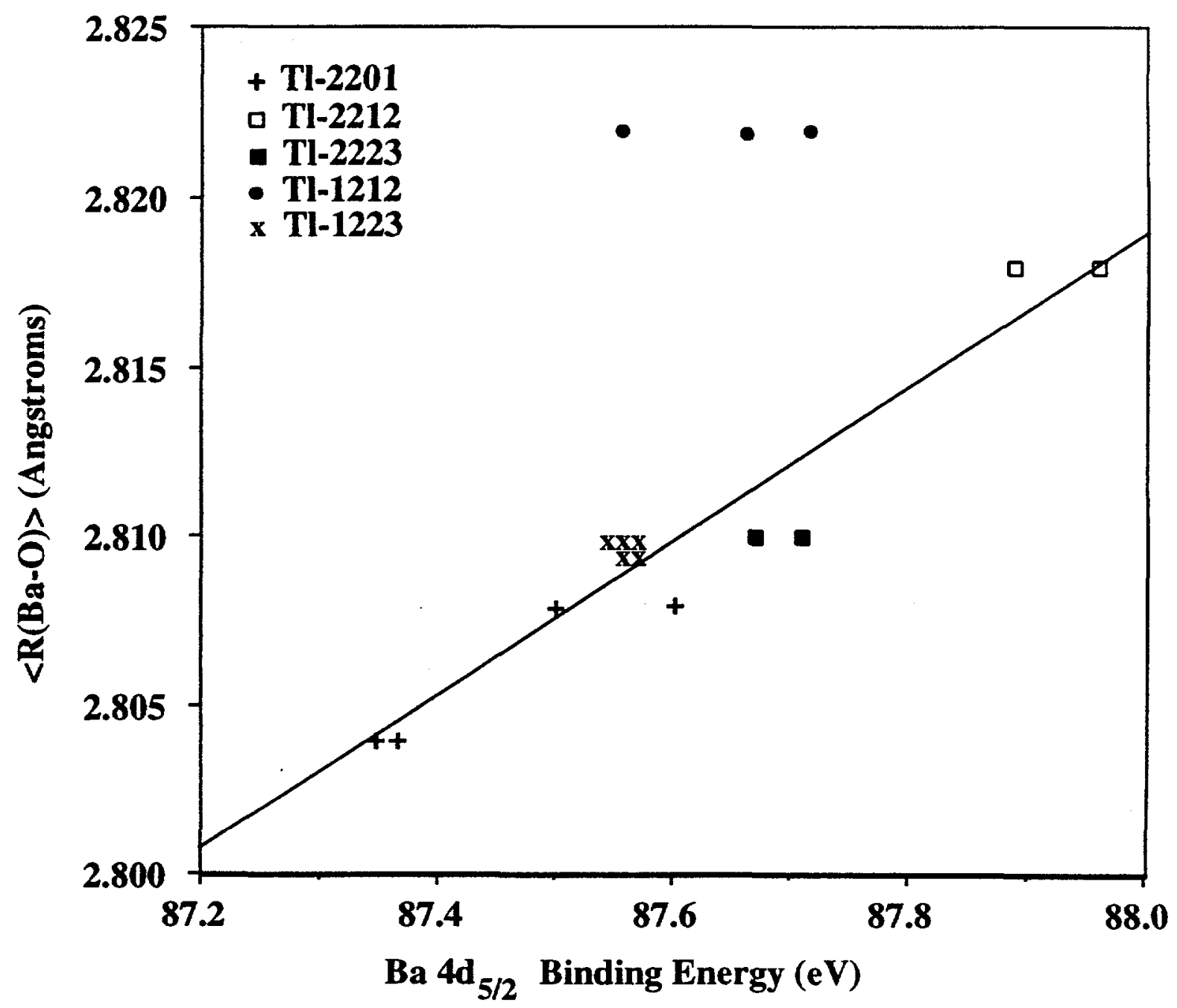




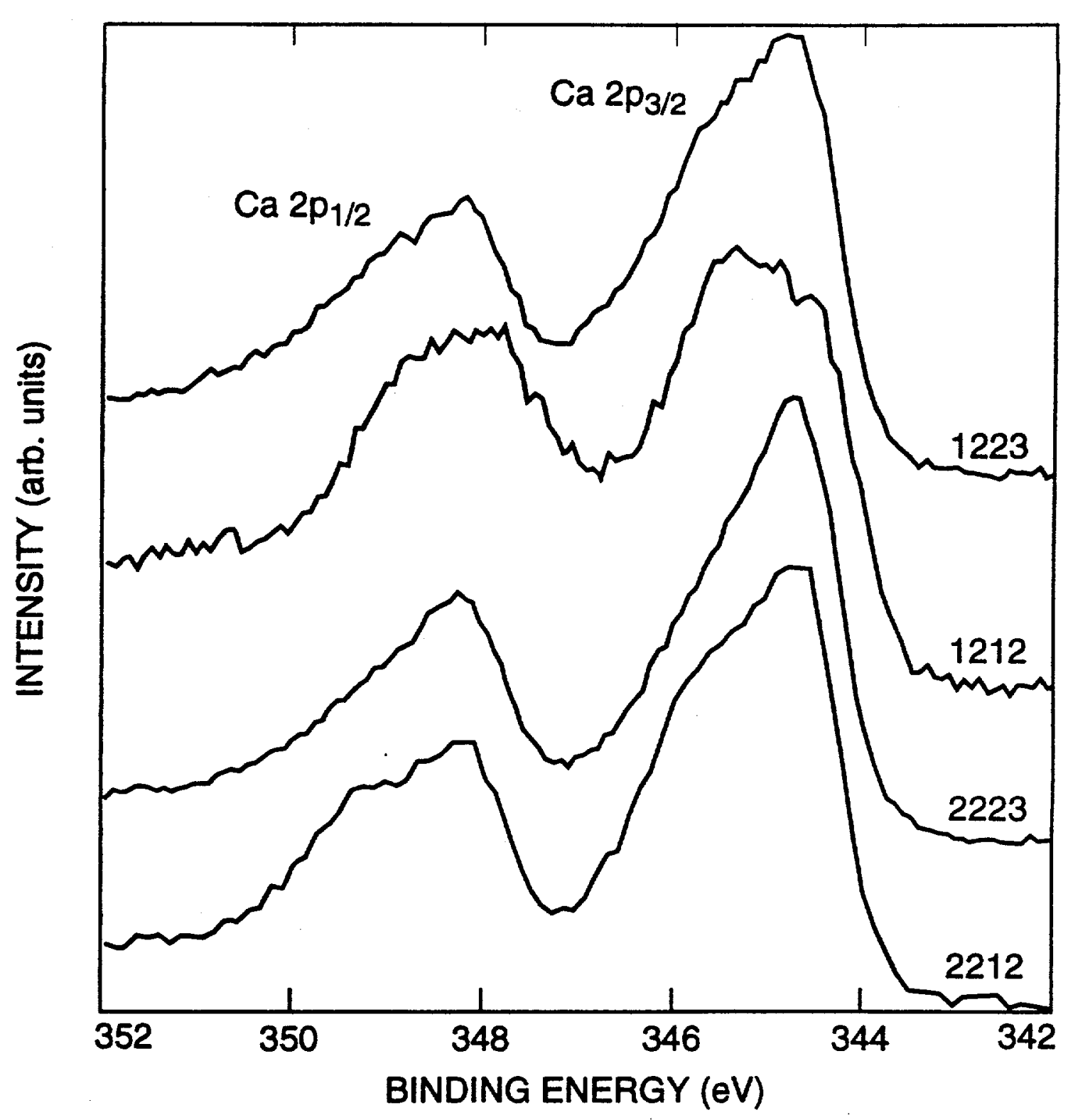




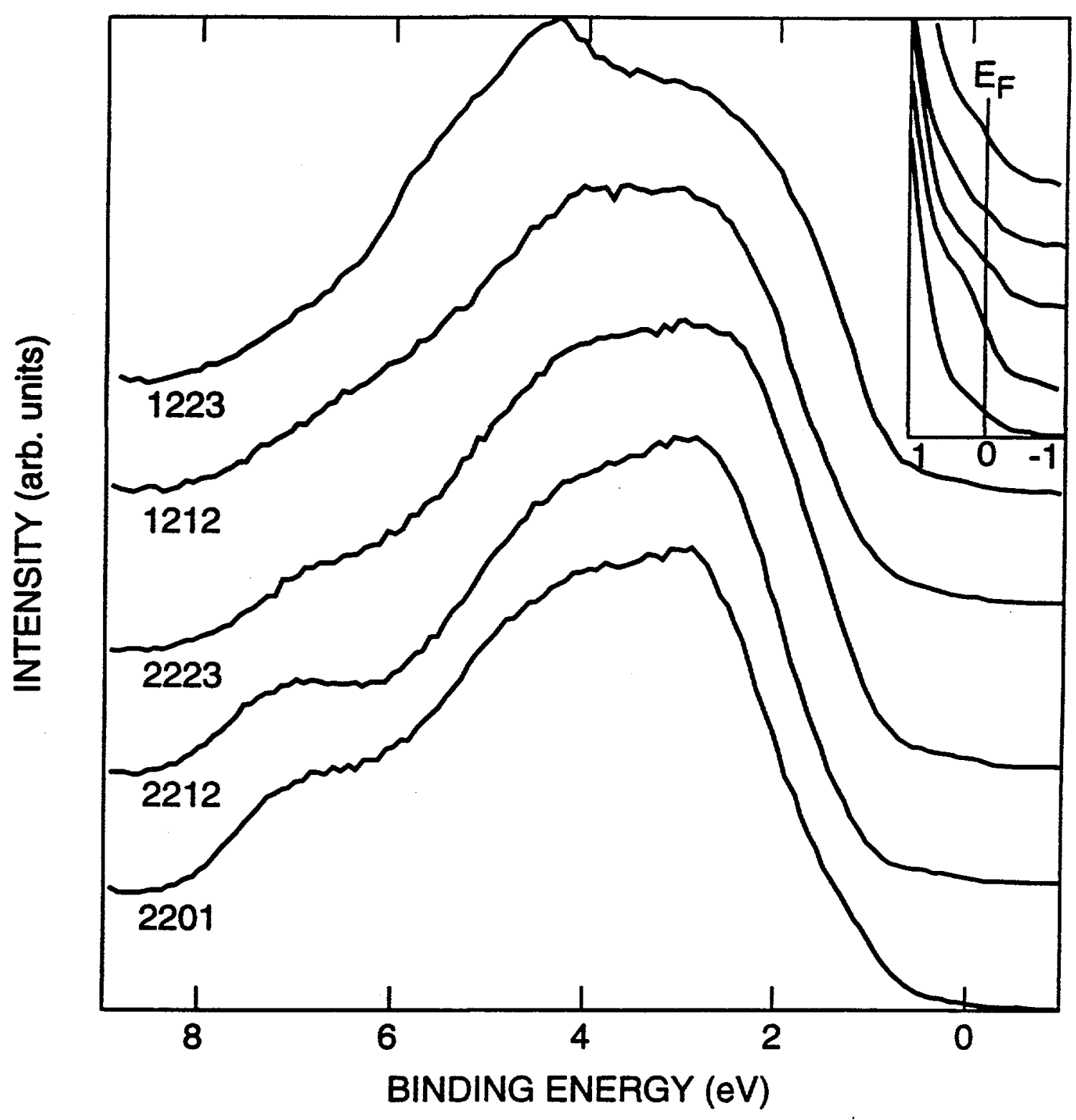

